\title{
ATELLIE
}

\section{Análise da Distribuição Espacial do Sistema Turístico de Juiz de Fora / MG}

\author{
Analysis of the Spatial Distribution of the Tourism System in \\ Juiz de Fora/MG
}

\section{Análisis de la Distribución Espacial del Sistema Turístico de Juiz de Fora/MG}

\author{
Thiago Duarte Pimentel \\ Universidade Federal de Juiz de Fora \\ thiago.pimentel@ich.ufjf.br
}

\begin{abstract}
Resumo
Este trabalho apresenta a análise espacial do sistema turístico/SISTUR a partir da produção cartográfica, temática e agregado, de seus equipamentos turísticos. $\mathrm{O}$ quadro teórico emerge na interface entre a administração, com ênfase na gestão pública, a geografia e o turismo, explorando o tema da aglomeração produtiva. Metodologicamente realizou-se um estudo de caso no locus de Juiz de Fora/MG, valendo-se de um banco de dados preexistente com os principais componentes do SISTUR em tela - em termos de equipamentos públicos e privados - de onde foram extraídos 100 itens mais representativos (amostra). Procedeu-se à geolocalização dos spots, via recuperação de informações disponíveis pelo sistema google Earth e, em casos específicos, via o georreferenciamento in locu de pontos não disponíveis. De posse das coordenadas dos 100 spots identificados, procedeu-se a produção de 18 cartas temáticas, por meio do software QGIS, setoriais e gerais, organizadas e analisadas segundo três princípios: o tipo de equipamento do sistema turístico; regiões de planejamento municipal, e concentração e centralidade. Tais mapas permitiram identificar a concentração da atividade em zonas: de alta, média e baixa incidência, cada qual requerendo um tipo de ação. Conclui-se que tais informações são estratégicas e necessárias para o fornecimento de informação qualificada necessária a tomada de decisão e intervenção no SISTUR em tela, visando o pleno desenvolvimento de suas potencialidades.
\end{abstract}

Palavras-chave: Sistema Turístico/SISTUR. Análise Espacial. Geolocalização. Mapas. Equipamentos Turísticos.

\footnotetext{
Abstract

This paper presents a spatial analysis of a tourism system/SISTUR, based on the thematic and aggregated cartography from the main components of the SISTUR. The theoretical framework emerges in the interface between administration, with emphasis on public management, geography and tourism, applied to the topic of
} 
clusters' economy. Methodologically, a case study was carried out in the locus of Juiz de Fora/MG, using a pre-existing database with the main components of SISTUR - in terms of public and private equipment - from where 100 more representative items were extracted, as a sample. We have proceeded to the geolocation of the spots, via recovery of available information using the Google Earth database system and, in some specific cases, in locu georeferencing from some spots whose information wasn't available. Using that coordinates of the 100 identified spots, 18 thematic and general maps were produced using QGIS software, organized and analyzed according to three main categories: the type of equipment of the tourism system; municipal planning regions, and concentration and centrality of the attributes. These maps allowed identifying the concentration of activity in zones: high, medium and low incidence, each one requiring a proper type of action. It is concluded that such information is strategic and necessary for the supply of qualified information necessary for decision making and intervention in the above mentioned SISTUR, in order to better explore the potentialities of that system.

Keywords: Tourism System/SISTUR. Spatial Analysis. Georeferencing process. Maps. Touristic Infrastructre.

\section{Resumen}

El presente documento presenta el análisis espacial de un sistema turístico/SISTUR, basada en la cartografía generada a partir de los equipamientos turísticos de dicho sistema. El marco teórico descansa sobre la interfaz entre la administración, con énfasis en la gestión pública, la geografía y el turismo, explorando el concepto de aglomeración productiva. Metodológicamente, se realizó un estudio de caso en la ciudad de Juiz de Fora/MG, utilizando una base de datos preexistente con los principales componentes de SISTUR - en términos de equipo público y privado - de donde se extrajeron 100 itens más representativos, como una muestra. Los spots fueran geolocalizados mediante la recuperación de la información disponible ya existente en el sistema Google Earth a lo cual si añadió la georeferenciación in locu de puntos no disponibles. Con las coordenadas a la mano de los 100 puntos identificados, se elaboraron 18 mapas sectoriales y temáticos generales, usando el software QGIS, organizados y analizados de acuerdo con tres principios: el tipo de equipamiento del sistema turístico; las regiones de planificación municipal, y la concentración y centralidad de los atributos. En estos mapas se identificó la concentración de la actividad en zonas de alta, media y baja incidencia, cada una de las cuales requiere un tipo de acción. Se concluye que dicha información es estratégica y necesaria para el suministro de información calificada necesaria para la toma de decisiones e intervención calificad en dicho SISTUR, con vistas a mejor explorar lo potencial de desarrollo existente.

Palabras clave: Sistema Turístico/SISTUR. Análisis Espacial. Geolocalización. Mapas. Equipamentos Turísticos.

\section{Introdução}

Em que pese seu surgimento histórico a partir da confluência de técnicas e parâmetros de análise derivados da geografia e economia, o campo de estudos da análise espacial de fenômenos é amplo, diverso e multifacetado segundo seus objetos e possibilidades analíticas. Nestas áreas a literatura sobre o tema é extensa e, de certo modo, já conta com escolas, ramificações e especificidades técnicas e metodológicas próprias. 
Inversamente, em campos científicos mais recentes, como o do turismo, análises de distribuição espacial de fenômenos são ainda pontuais (PRAT; CÀNOVES, 2014) e se dispersam entre uma ampla gama de aplicações que vão da espacialização e descrição dos dados em um dado contexto com vistas à gestão e otimização dos fatores produtivos (FERNANDES et al., 2012; PÍCOLO; GÂNDARA, 2013; MARTÍN; RIVERO; GALLEGO, 2017), passando pela discussão metodológica - via procedimentos, técnicas ou indicadores (SANTO, 2012), ou via a elaboração e representação cartográfica adequada dos dados e fenômenos especializados (BALSABARREIRO; LOIS-GONZÁLEZ, 2010) - ou ainda por reflexões teóricas sobre as possibilidades de uso, rearticulações e reapropriações espaciais e suas implicações (SOTRATTI, 2014).

O turismo tem uma raiz marcadamente territorial (CRUZ, 2003; BIZINELLI et al., 2016; MARTÍN; RIVERO; GALLEGO, 2017), dado que tanto a oferta quanto a demanda se distribuem sobre um território que conforma o espaço turístico. Devido a esta particularidade, a análise espacial deve desempenhar um papel primordial em qualquer atividade turística (MARTÍN; RIVERO; GALLEGO, 2017). Bizinelli et al. (2016, p. 23) acrescentam que "[...] o estudo da dinâmica da distribuição espacial desses empreendimentos é imprescindível, pois faz com que se compreenda de que forma a cidade se configura para o recebimento dos turistas e de que forma a oferta da mesma vem sendo trabalhada".

Ainda assim, a análise do turismo a partir de uma perspectiva geográfica não é uma perspectiva dominante nesta área. A perspectiva econômica e de gestão é, de longe, a predominante na academia turística em plano mundial, sendo a perspectiva análise espacial, e sobretudo, dentro desta, aquela dedicada ao uso de técnicas cartográficas tradicionais e de geoprocessamento digital, apenas uma fração marginal (PIMENTEL, 2016; PIMENTEL; CARVALHO, 2016).

Nos poucos estudos existentes sobre análise espacial do turismo, no Brasil, é possível identificar a existência de trabalhos dedicados à distribuição espacial da oferta turística (FERNANDES et al., 2012; PÍCOLO; GÂNDARA, 2013) e, com menor frequência, da demanda turística (BRAGA; GONTIJO; VIEIRA, 2015) ${ }^{1}$. No entanto, os estudos de distribuição espacial da oferta turística têm sido apresentados considerando elementos específicos daquela oferta, por exemplo equipamentos de hospedagem (PÍCOLLO; GÂNDARA, 2013), ou ainda priorizando grandes escalas espaciais, por exemplo, estados e regiões (FERNANDES et al., 2012). Braga, Gontijo e Vieira (2015) levantam uma hipótese importante que ressalta precisamente a relevância da análise espacial das atividades turísticas.

\footnotetext{
1 Um indicador desta produção marginal pode ser encontrado analisando-se a distribuição dos artigos publicados em periódicos científicos da área de turismo. A título de ilustração, tomando como base os 11.972 artigos publicados em 40 revistas predominantemente brasileiras, mas também latino e ibero americanas que compõem o portal Publicações de Turismo, é possível verificar a existência de 8 artigos recuperados a partir do termo de busca "análise espacial" (ou 13 pelo termo "distribuição espacial" dos quais há uma sobreposição de $90 \%$ ), e 84 resultados para busca booleana retornando livremente apenas um dos termos, o que mesmo neste último cenário representaria menos de $0,7 \%$ do volume de material publicado. [Consulta realizada em 27.8.20].
} 
Apesar do senso comum encarar o turismo como uma atividade reprodutora do espaço urbano (por meio da introdução de práticas como a prestação de serviços, especulação imobiliária, aculturação etc.), o que será proposto é um exercício contrário: pensar que o espaço urbano atua como produtor / reprodutor da atividade turística em espaços rurais e naturais. Considera-se, neste caso, a infraestrutura em áreas urbanizadas e semiurbanizadas como fator primordial para o desenvolvimento da atividade turística (BRAGA; GONTIJO; VIEIRA, 2015, p. 689).

Todavia, análises focadas em um sistema turístico e que consideram seus componentes ainda representam um campo em aberto. Nesse sentido, o presente estudo tem como objetivo realizar uma análise espacial do sistema turístico, em um único destino, a partir de uma amostra baseada em seus componentes principais, a saber: meios de hospedagem, de transporte, de alimentação, atrativos turísticos de serviços de apoio geral, considerando o caso da cidade de Juiz de Fora (MG).

O quadro teórico em que se embasa este estudo resgata as contribuições na interface entre a administração, com ênfase particular na gestão pública, a geografia e o fenômeno turístico. Especificamente, valendo-se das discussões precedentes acerca de planejamento e gestão de destinos turísticos, identifica-se como um dos desafios presentes inventariados pela literatura - em especial no tocante a realidade brasileira - 0 entendimento de se, e como, a localização espacial da oferta turística incide sobre o planejamento e gestão do destino.

Tentando contribuir com este tema, o presente estudo deteve-se na primeira parte deste problema, qual seja, a produção de informações geográficas específicas para a análise turística e a sua possibilidade de uso para a gestão do sistema turístico. Portanto, além de contribuir teoricamente para o ainda limitado acervo de estudos dedicados à análise espacial do turismo, enfocando particularmente na distribuição de todos os componentes principais em um mesmo destino - o que permite ver a espacialização da oferta real e traçar diretrizes de ação -; este estudo também será potencialmente útil de forma prática para órgãos públicos de gestão e controle da atividade (municipais e/ou estaduais), e para a iniciativa privada, que poderá formatar novos produtos, roteiros e serviços - em função de sua proximidade, afinidade e complementaridade - ao serem ofertados no destino.

\section{Análise Espacial como Ferramenta de Suporte ao Planejamento e Gestão de Destinos Turísticos}

A localização espacial das atividades socioeconômicas é tema de estudos desde o final do século XIX. Alfred Marshall (1982), por exemplo, formulou a tese de que a instalação de empresas de um mesmo setor nas proximidades umas das outras beneficiariam de externalidades positivas umas às outras como o acesso a clientes e a mão de obra rotativa, por exemplo, formando assim o que ele denominou de economias de aglomeração. 
Ao longo do século XX, a discussão alusiva aos temas de fronteira entre geografia e a atividade econômica evolui bifurcando-se em duas grandes vertentes: uma chamada economia espacial, relacionada à localização espacial das atividades propriamente dita, onde o foco é a determinação ótima do ponto no espaço onde uma empresa deve se localizar, levando-se em conta, frequentemente, fatores como malha de transporte, acesso a recursos e a mercados consumidores, etc.

Uma segunda vertente, da geografia econômica, também tem se dedicado àquela fronteira de estudos, e, embora alguns de seus trabalhos adotem a perspectiva de otimização produtiva, seu foco reside na exploração, de forma mais ampla, de sistemas e circuitos econômicos, onde um conjunto mais extenso de variáveis (tais como: dinâmicas e relações intra e interorganizacionais, influência do estado e políticas públicas, efeitos da concentração espacial da atividade econômica e desenvolvimento, etc.) se apresenta para análise, que por sua vez, também pode assumir outras perspectivas, como uma análise política ou ainda uma análise sociológica (interpretativa a partir da visão dos stakeholders envolvidos) que não a de análise de eficiência locacional.

Se no início do século XX a análise espacial das atividades econômicas estava mais fortemente relacionada ao registro do sistema "firma", ou seja, adotando esta unidade de análise como eixo central de discussão, é a partir do pós-guerra (1945 em diante) que uma orientação sistêmica voltada à análise macro (econômica, política e social) tomará lugar. Neste contexto, a tese dos polos regionais de desenvolvimento (PERROUX, 1967) assumirá lugar de destaque e, aos poucos, se imporá como um modelo dominante - sobretudo para autores ligados à geografia e à administração pública - enquanto os estudos de Von Thunen (1966), de Weber (1969), e seus seguidores serão progressivamente enquadrados numa perspectiva teórica-metodológica de análise estritamente econômica.

Na segunda metade do século XX e, em particular, a partir dos anos 1990, após ampla expansão e diversificação dos estudos em perspectivas e modelos de análise, é que haverá um resgate das teses originais dos distritos marshallianos e tentativas de reinterpretação e síntese das contribuições subsequentes, numa espécie de sistematização, classificação e ordenamento da discussão. É num contexto de preocupação com uma espécie de competitividade sistêmica, não de uma empresa, mas de um conjunto de empresas que atuam em uma mesma zona espacial, que trabalhos como os Lastres e Cassiolato (2004) proporão conceitos como sistemas locais de produção, sistemas inovativos locais, sistemas de produção e inovação locais (SPILL), arranjos produtivos locais, entre outros. Aspectos relevantes sobre estas abordagens são observadas nos quadros 1 e 2 .

Se aquelas discussões se fizeram de forma mais presente e intensa nos campos da economia, da geografia e, progressivamente, em boa medida no campo da administração - área responsável pela retomada e renovação do tema, a partir do final dos anos 1990, com destaque para trabalhos acadêmicos recentes indicam que o setor de serviços também possui suas próprias estratégias de aglomeração - estudos destas 
temáticas no campo do turismo são mais escassos, recentes e específicos (PRAT; CÀNOVES, 2014). Ainda assim é possível identificar trabalhos que são animados pela discussão relativa à localização socioeconômica das atividades e seus efeitos - ainda que não necessariamente se identifique ou relacione claramente sua filiação teórica dentro de linhas de estudos precedentes.

Quadro 1: Aspectos comuns das abordagens de sistemas produtivos locais: redes, clusters, arranjos produtivos locais e distritos industriais.

\begin{tabular}{|c|c|c|c|c|}
\hline Termos & Características & Autores & Peculiaridades & Aspectos Comuns \\
\hline Clusters & $\begin{array}{l}\text { Aglomerações geográficas de } \\
\text { grandes, médias ou pequenas } \\
\text { empresas, sejam relacionadas ou } \\
\text { complementares }\end{array}$ & $\begin{array}{l}\text { Porter; } \\
\text { Chandler, } \\
\text { Hagstrom } \\
\text { Junior e } \\
\text { Solvell }\end{array}$ & $\begin{array}{l}\text { - Empresas de } \\
\text { grande porte } \\
\text { complementadas } \\
\text { por outras } \\
\text { menores } \\
\text { - Acordos } \\
\text { formais Cluster e } \\
\text { econômicos } \\
\text { - Realidade } \\
\text { norte-americana }\end{array}$ & 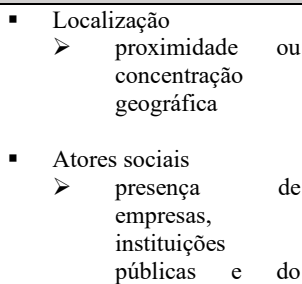 \\
\hline $\begin{array}{l}\text { Distrito } \\
\text { industrial }\end{array}$ & $\begin{array}{l}\text { Pequenas e médias empresas de } \\
\text { um mesmo negócio, especializadas } \\
\text { em etapas diferentes do processo } \\
\text { produtivo e envolvidas por fortes } \\
\text { relações sociais e econômicas }\end{array}$ & $\begin{array}{l}\text { Pyke e } \\
\text { Sengenber } \\
\text { ger; } \\
\text { Becattini }\end{array}$ & $\begin{array}{l}\text { - Relações densas } \\
\text { - Forte papel da } \\
\text { reputação e da } \\
\text { confiança } \\
\text { - Relações sociais } \\
\text { potencializando as } \\
\text { econômicas } \\
\text { - } \\
\text { Descentralização } \\
\text { do poder Distrito } \\
\text { industrial } \\
-\quad \text { Realidade } \\
\text { italiana }\end{array}$ & $\begin{array}{l}\text { terceiro setor } \\
\text { (associações, } \\
\text { sindicatos, } \\
\text { universidades, } \\
\text { centros de } \\
\text { pesquisa, suporte } \\
\text { financeiro, ONGS, } \\
\text { etc.) } \\
\text { - Características } \\
\text { Especialização, de } \\
\text { misto } \\
\text { cooperação e } \\
\text { competição entre } \\
\text { as empresas }\end{array}$ \\
\hline $\begin{array}{l}\text { Arranjo } \\
\text { produtivo } \\
\text { local }\end{array}$ & $\begin{array}{l}\text { Pequenas e médias empresas } \\
\text { manufatureiras, concentradas por } \\
\text { um negócio comum, com relações } \\
\text { formais e informais e cultura } \\
\text { compartilhada }\end{array}$ & $\begin{array}{l}\text { Caporali e } \\
\text { Volker; } \\
\text { Cassiolato } \\
\text { e Lastres }\end{array}$ & $\begin{array}{l}- \text { Misto das } \\
\text { características } \\
\text { clusters e de } \\
\text { distritos } \\
\text { industriais local } \\
\text { - Adaptação à } \\
\text { realidade } \\
\text { brasileira } \\
\text { Rede de empresas }\end{array}$ & $\begin{array}{r}\text { Cooperação entre } \\
\text { empresas e } \\
\text { instituições de } \\
\text { interesse público } \\
\text { Canais de } \\
\text { comunicação e } \\
\text { confiança entre } \\
\text { firmas } \\
>\quad \text { Identidade cultural }\end{array}$ \\
\hline $\begin{array}{l}\text { Rede de } \\
\text { empresas }\end{array}$ & $\begin{array}{l}\text { Alianças estratégicas } \\
\text { interorganizacionais de empresas } \\
\text { que } \\
\text { interagem e cooperam buscando } \\
\text { estabelecer vantagem competitiva. } \\
\text { Podem ser de diferente porte, com } \\
\text { diferentes relações de poder, } \\
\text { centralização ou não da hierarquia, } \\
\text { aglomeradas ou dispersas } \\
\text { territorialmente }\end{array}$ & $\begin{array}{l}\text { Powell; } \\
\text { Gullati, } \\
\text { Nohria, } \\
\text { Zaheer; } \\
\text { Ebers } \\
\text { e Jarillo; } \\
\text { Miles e } \\
\text { Snow }\end{array}$ & $\begin{array}{l}\text { - Diferentes } \\
\text { portes, com } \\
\text { diferentes } \\
\text { relações de poder, } \\
\text { centralização ou } \\
\text { não da hierarquia, } \\
\text { aglomeradas ou } \\
\text { dispersas } \\
\text { territorialmente }\end{array}$ & 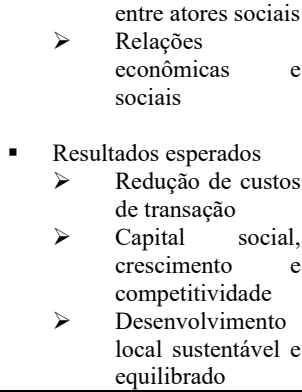 \\
\hline
\end{tabular}

Fonte: adaptado dos quadros 2, 3 e 4 de Costa e Souto-Maior (2006, p. 7; 13; 14). 
No que tange especificamente aos arranjos produtivos locais - uma das terminologias mais adotadas no Brasil, senão a mais - vale a pena ressaltar o caráter relativo ao grau de organização (desde mais espontâneo ou informal, por um lado, ao mais sistemático ou organizado, por outro) e neste caso, ainda há a possibilidade de se especificar o grau e hierarquização dentro do processo de organização (PEREIRA; GUIMARÃES; GOMES, 2011). Tais elementos são importantes, pois tanto o grau de organização quanto de hierarquização das relações dentro de uma organização (ou cadeia produtiva) permitem a criação e utilização de mecanismos elaborados precisamente para reforçar a colaboração entra e interorganizacional (PIMENTEL; BARBOSA; CARVALHO, 2017).

Quadro 2: Tipologia de classificação de formas de aglomeração versus abordagem conceitual.

\begin{tabular}{|c|c|c|}
\hline Tipologia & $\begin{array}{c}\text { Classificação APL } \\
\text { pela literatura }\end{array}$ & Abordagem conceitual \\
\hline $\begin{array}{l}\text { Arranjos } \\
\text { informais }\end{array}$ & $\begin{array}{l}\text { Sobrevivência } \\
\text { Subsistência } \\
\text { Anarquia das trocas } \\
\text { Governança } \\
\text { mercadológica }\end{array}$ & $\begin{array}{l}\text { - Muitas pequenas e microempresas } \\
\text { - Poucas barreiras de entrada } \\
\text { - Competição superara a colaboração } \\
\text { - Baixo fluxo de informação e conhecimento interfirmas } \\
\text { - Defasagem tecnológica e baixa capacidade inovativa } \\
\text { - Pouca qualificação dos profissionais na gestão das } \\
\text { empresas } \\
\text { - Inexistência de subsídios financeiros } \\
\text { - Baixa competitividade }\end{array}$ \\
\hline $\begin{array}{l}\text { Arranjos } \\
\text { organizados }\end{array}$ & $\begin{array}{l}\text { Auto-organização } \\
\text { heterárquica Cluster } \\
\text { organizado } \\
\text { Rede } \\
\text { Quasi-hierarquia, } \\
\text { Auto-organização } \\
\text { heterárquica } \\
\text { Nível horizontal de } \\
\text { organização } \\
\text { industrial } \\
\text { Distritos Industriais } \\
\text { Marshallianos } \\
\text { Bottom-up }\end{array}$ & $\begin{array}{l}\text { - Co-opetição (colaboração e competição ao mesmo } \\
\text { tempo) } \\
\text { - Especialização interfirmas ao longo da cadeia produtiva } \\
\text { - Compartilhamento de informações e conhecimentos e } \\
\text { capacitação dos profissionais de forma conjunta } \\
\text { - Formação de agências de financiamento e crédito } \\
\text { - Decisões locais e compartilhamento de recursos } \\
\text { (matéria-prima e equipamentos) } \\
\text { - Externalidades e internalização de melhores práticas } \\
\text { - Eficiência coletiva }\end{array}$ \\
\hline $\begin{array}{l}\text { Arranjos } \\
\text { inovativos }\end{array}$ & $\begin{array}{l}\text { Arranjos inovativos } \\
\text { Redes de inovação }\end{array}$ & $\begin{array}{l}\text { - Cooperação e confiança interempresarial, } \\
\text { - Compartilhamento de P\&D } \\
\text { - Capacidade de adaptação e flexibilidade gerencial e } \\
\text { técnica } \\
\text { - Alto fluxo de informação, conhecimento e } \\
\text { aprendizagem coletiva; capacidade absortiva } \\
\text { - Competitividade em produtos e processos e nichos de } \\
\text { mercado, qualidade e especialização produtiva } \\
\text { - Subsídios para geração de novos produtos/serviços com } \\
\text { alto valor agregado } \\
\text { - Alta qualificação interfirmas e gerencial, mão-de-obra } \\
\text { especializada }\end{array}$ \\
\hline
\end{tabular}




\begin{tabular}{|c|c|c|}
\hline Tipologia & $\begin{array}{c}\text { Classificação APL } \\
\text { pela literatura }\end{array}$ & Abordagem conceitual \\
\hline $\begin{array}{l}\text { Arranjos } \\
\text { hierárquicos }\end{array}$ & $\begin{array}{l}\text { Distritos industriais } \\
\text { centroradiais } \\
\text { Clusters avançados } \\
\text { de produção em } \\
\text { massa } \\
\text { Hierarquia } \\
\text { organizacional } \\
\text { Integração vertical } \\
\text { Arranjos Fordistas } \\
\text { Top-down }\end{array}$ & $\begin{array}{l}\text { - Empresa âncora no processo produtivo, fornecedores } \\
\text { próximos e atividades correlatas } \\
\text { - Centralização das decisões } \\
\text { - Alta qualificação e competitividade dos produtos } \\
\text { - Produtos padronizados e em massa } \\
\text { - Atuação por escopo, segmentação da produção } \\
\text { - Compartilhamento de P\&D, liderado pela empresa- } \\
\text { chave } \\
\text { - Liderança em custo } \\
\text { - Qualificação da mão-de-obra } \\
\text { - Altos investimentos em infra-estrutura local } \\
\text { - Acesso a recursos e financiamentos }\end{array}$ \\
\hline $\begin{array}{l}\text { Arranjos } \\
\text { Subsidiados }\end{array}$ & $\begin{array}{lr}\text { Zona } & \text { de } \\
\text { Processamento } & \text { da } \\
\text { Exportação } & \\
\text { Parques } & \\
\text { tecnológicos } & \text { ou } \\
\text { incubadoras } & \\
\text { ancorados } & \text { pelo } \\
\text { Estado } & \\
\text { Clusters } & \text { de } \\
\text { corporações } \\
\text { transnacionais } \\
\text { Arranjos ancorados } \\
\text { pelo Estado }\end{array}$ & $\begin{array}{l}\text { - Recebem incentivos para serem constituídos, subsídios } \\
\text { ao funcionamento } \\
\text { - Acesso a recursos e financiamento de "cima para } \\
\text { baixo" } \\
\text { - Pouca autonomia e centralização das decisões, gestores } \\
\text { externos } \\
\text { - Inserção externa de valores, pouca relevância da cultura } \\
\text { local } \\
\text { - Políticas externas e intervenção nos processos } \\
\text { - Descontinuidade dos investimentos, conforme interesse } \\
\text { externo } \\
\text { - Desenvolvimento de infra-estrutura e criação de novos } \\
\text { empregos } \\
\text { - Qualificação da mão-de-obra e criação de centros para } \\
\text { desenvolvimento (escolas profissionalizantes) } \\
\text { - Acesso ao mercado externo } \\
\text { - Competitividade dos produtos, valor agregado e } \\
\text { qualidade }\end{array}$ \\
\hline
\end{tabular}

Fonte: Pereira, Guimarães e Gomes (2011, p. 8-9).

No cenário internacional, estes estudos parecem dedicar-se a uma perspectiva mais economicista, seja pelo viés teórico-metodológico, seja pelo nível de análise (firmas), o tipo de sistemas analisados (empresas privadas), ou ainda - e de forma mais claramente vinculada àquela corrente - pelo viés otimizador em termos da alocação espacial de recursos ${ }^{2}$ e sistemas. Exemplos podem ser encontrados nos estudos de localização de filiais de hotéis de cadeias internacionais, de otimização e redução de rotas e malha de companhias áreas ou otimização da gestão de operações aeroportuárias.

\footnotetext{
${ }^{2}$ No plano intra organizacional o foco recai sobre a otimização das atividades de gestão de operações, sendo comumente relacionado a área de logística e administração de materiais, enquanto que no âmbito sistêmico ou interorganizacional o foco recai sobre os relacionamentos inter-firmas e comumente este tipo de análise pode ser mais facilmente encontrado nas áreas de estratégia (e competitividade) - para os pesquisadores vinculados à administração - ou custos de transação - no caso de pesquisadores originalmente ligados à economia. Obviamente, no contexto atual de fragmentação disciplinar, tais identificações perdem progressivamente sua força à medida que novos cruzamentos entre essas áreas e, sobretudo, entre outras áreas e estas são produzidos.
} 
Martín, Rivero e Gallego (2017, p. 549) evidenciam de forma sintética a problemática da análise espacial. Para os autores:

La actividad turística se ha analizado profusamente desde una óptica estadística tal como lo demuestra la enorme variedad de estudios que, desde diferentes perspectivas, aplican diversos análisis a través de este conjunto de técnicas sobre la mayor parte de variables e indicadores del turismo. Entre todos ellos destaca el análisis simultáneo sobre múltiples variables aplicando técnicas como el análisis factorial, ya sea exploratorio ya sea confirmatorio, el análisis clúster, etc. [...] Asimismo, son destacables los estudios que se centran en la utilización de los parámetros estadísticos descriptivos enfocados normalmente al análisis de la oferta. Mientras tanto, el análisis inferencial suele aplicarse a análisis de demanda, en los que cobra especial importancia la predicción, no solo del número global de visitantes en futuras temporadas, sino del vector de características de cada uno de los turistas venideros, para una mejor adecuación entre la oferta y la demanda (Hernández, 2002). Pese a estas tres aplicaciones diferentes y contrastadas del análisis estadístico al sector del turismo, conviene reseñar que desde hace más de dos décadas, en los estudios empíricos, los investigadores buscan detectar posibles asociaciones entre las características regionales y los resultados observados en diferentes localizaciones geográficas (Powell, 1991; Mennis, 2005; Taylor, 2008; Yi-Ju Chen, 2012), aspecto que implica necesariamente la utilización de estadística espacial.

Outro tema importante que recorre ao estudo da análise espacial é o da competitividade turística. Ao analisar a competitividade no planejamento turístico espacial, Santo (2012) a considera uma valiosa informação para conhecer as capacidades do território e determinar quais podem posicionar-se como verdadeiras vantagens competitivas. Com base no contexto empírico de Alicante (Espanha) para validação de sua proposta metodológica de análise da concentração espacial e sua relação com a competitividade, o autor conclui que quatro variáveis (recursos naturais, recursos histórico-culturais, oferta de alojamento e demanda turística), podem ser verificadas em termos de sua concentração espacial e que estão relacionadas com o nível de competitividade do destino.

Balsa-Barreiro e Lois-González (2010), ao analisarem a produção cartográfica da empresa pública de turismo da Comunidad Autónoma de Galicia (Turgalicia), abordam o dilema prático entre a representação exata e fidedigna da realidade (que exige um conhecimento específico prévio do leitor/usuário) e o viés mais estilístico ou artístico na representação (que a simplifica e torna mais propensa a ser aceita e interpretada mais facilmente pelo senso comum, mas às expensas da perda de sentido e exatidão), dilema este que se apresenta, em sua visão, de forma mais emblemática no tipo de representação elaboração para o uso turístico. Em seus achados, observaram que os problemas mais comuns eram: 1) ausência de escalas, 2) emprego de elementos cartográficos 
inadequados (pobre paleta de cores e simbologia), 3) ausência de clareza sobre quem dirigiu a cartografia, 4) informação desatualizada ou errônea, e 5) produção da cartografia turística baseada em divisões administrativas de pouca utilidade para o propósito almejado (por exemplo, com grande detalhe ou cuja divisão não afeta $o$ fenômeno turístico).

Ao atacar o problema do crescente uso da cartografia por parte de diferentes atores (em particular de organismos, instituições) estes autores afirmam que tal crescente uso não tem sido feito de forma adequada o que gera como consequência uma interpretação pouco veraz e eventualmente distorcida, sendo possível identificar 4 tipos de fatores: 1) ausência de normas de padronização; 2) falta de acessibilidade ao uso desta técnica devido ao seu elevado preço e exclusividade (conhecimento específico restrito); 3) o tratamento da informação gráfica e alfanumérica de forma separada até o aparecimento dos Sistemas de Informação Geográfica (SIG); e 4) o senso comum de que os mapas não passariam de simples desenhos ou croquis, e que este tipo de representação (ainda que não muita específica) já seria suficiente (BALSA-BARREIRO; LOIS-GONZÁLEZ, 2010).

Prat e Cànoves (2014) consideram que houve um ressurgimento da problemática da localização espacial das atividades econômicas, a partir dos anos 1990, sobretudo a partir de um viés empresarial, mas ainda restrito no âmbito do turismo. Visando fornecer uma contribuição teórica e prática para a área - sobretudo no contexto da crise econômica de 2013 - os autores se questionam porque os equipamentos turísticos se localizam em um lugar ao invés de outro? E, as forças de aglomeração podem atrair os estabelecimentos turísticos para a formação de concentrações territoriais? Com base no estudo empírico do turismo de montanha nos Pirineus (Espanha), os autores analisaram a localização dos equipamentos turísticos e identificaram uma oferta em forma de aglomeração, ainda que não tão expressiva (no entanto, ressaltam que apesar disso ela é suficiente para criar economias de escala mínimas).

Tomando como contexto empírico de análise o caso da província de Cáceres (Espanha), Martín, Rivero e Gallego (2017) analisaram a problemática da desarmonia na distribuição espacial da oferta de alojamentos rurais em face dos atrativos naturais. Enquanto os atrativos mais relevantes tendem a se concentrar em áreas com maior abundância hidrográfica e menos opções de alojamento, a maior oferta de alojamentos está longe desses atrativos. Uma opção para lidar com o tema seria o incremento da oferta de alojamentos rurais, mais próximos aos atrativos. Para tanto, os autores estudaram a distribuição espacial dos alojamentos (reais e potenciais) e da oferta de atrativos e concluíram que a otimização da oferta de alojamentos rurais existentes pode ser obtida pela introdução de novos meios que estão subaproveitados. 
No Brasil ${ }^{3}$, dentro de uma perspectiva tendente a análise espacial funcional e otimizadora, se encontram estudos sobre a localização espacial de hotéis, restaurantes, atrativos turísticos e da mão de obra empregada.

Píccolo e Gândara (2013) analisaram a evolução da distribuição espacial dos hotéis em redes no estado do Paraná, entre os anos de 1940 a 2010. Em seus achados detectaram que, embora o fenômeno possa ser remontado a 1940, foi somente a partir de 1990 que se inicia uma expansão mais significativa do número de hotéis em algumas cidades paranaenses, inclusive de redes internacionais, estando os mesmos presentes (à época do estudo) em apenas onze cidades do estado do Paraná. A análise da distribuição espacial dos hotéis, no caso em tela, permitiu a verificação da mais elevada incidência do fenômeno na capital e nas regiões mais intensas em serviços, o que sugere uma possível associação do tema com o turismo de negócios.

Em outro estudo, Fernandes et al. (2012) analisaram a distribuição espacial da oferta turística de regiões não prioritárias, (Curitiba e Região Metropolitana, Litoral, Campos Gerais e Foz do Iguaçu e Municípios Lindeiros), segundo a política estadual de turismo. Embora constatem em seus achados que a oferta turística das regiões não prioritárias está distribuída espacialmente de forma descontínua, dificultando assim o planejamento e a sua integração em regiões, rotas e produtos turísticos mais elaborados; há, por outro lado, uma oferta latente diferenciada - alusiva aos segmentos do turismo náutico e de pesca, e o turismo de compras - que pode ser melhor explorada e constituirse em enclaves específicos, aproveitando assim melhor as potencialidades regionais do estado do Paraná.

Bizinelli et al. (2016) analisaram a dinâmica da distribuição dos restaurantes da cidade de Curitiba, bem como das categorias de estabelecimentos presentes nos bairros no período de 1989 a 2014 ( 25 anos). Em sua visão, os estabelecimentos comerciais de alimentação são considerados relevantes dentro da atividade turística, pois podem ser avaliados tanto como um atrativo turístico, a partir da perspectiva da gastronomia como forma de se valorizar a cultura, como um equipamento turístico. Para o estudo, recorreram ao uso do Guia Quatro Rodas em três edições (1989/2001/2014), aliando a pesquisa documental a técnicas de análise espacial. Segundo os autores constata-se uma:

[...] predominância de restaurantes nos bairros do Centro, Batel e Santa Felicidade, sendo que há variações entre cada ano. Dentro das categorias se destacaram as pizzarias, as churrascarias e a comida italiana, com maior número de empreendimentos distribuídos pela cidade. Também se nota uma variação nas tendências de categorias dos estabelecimentos de alimentação comercial a cada edição analisada, no caso de 1989, além das

\footnotetext{
${ }^{3}$ A literatura brasileira pode ser razoavelmente percebida pela consulta ao portal publicações de turismo, que reúne todos os periódicos brasileiros relacionados ao turismo, além de alguns de outras países na América latina, Portugal e Espanha. Em consulta recente (27.8.20) foram recuperados 8 resultados diretamente relacionados com o termo de busca "análise espacial" e outros 84 indiretamente relacionados (mencionando apenas alguns dos termos em qualquer parte do documento).
} 
categorias mencionadas, destacaram-se restaurantes de pescados, casas de chá e confeitarias; em 2001, observou-se crescimento do número de estabelecimentos de alimentação com cozinha 'variada'; e em 2014, nota-se a forte tendência das 'comidinhas', como novo tipo de estabelecimento-tendência, bem como, a permanência das cozinhas variadas em destaque. Pode-se salientar que a existência de locais que ofertam uma alimentação de qualidade, localizados tanto próximos ao trabalho, quanto à moradia dos indivíduos, fez com que a alimentação fora do lar se tornasse um importante segmento da economia curitibana, fazendo com que mais estabelecimentos buscassem uma maneira de se divulgar (BIZINELLI et al., 2016, p. 24).

Braga, Gontijo e Vieira (2015), analisando a oferta de atrativos turísticos e sua relação com a demanda, trazem reflexões e alternativas para o entendimento da ação espacial do turismo. Analisado o caso da distribuição de atrativos na Serra do Cipó (MG), por meio do levantamento e mapeamento dos atrativos e equipamentos turísticos presentes na região do Parque Nacional da Serra do Cipó, os autores constataram que há regiões com melhores infraestruturas, e que por isso tendem a receber um fluxo maior de visitantes.

É por meio da análise da oferta de atrativos e equipamentos turísticos que foi possível, mesmo que de forma embrionária, identificar a importância que cada um tem para o desenvolvimento da atividade turística. Apesar de muito comum a suposição de que o fluxo de visitante determina o ritmo e grau de transformações nos núcleos receptores, observa-se que são as respostas do núcleo receptor que determinam a estagnação ou o desenvolvimento da atividade." [...] "A indução do processo de transformação espacial que pode ser percebida por abertura de empreendimentos e equipamentos turísticos depende basicamente de como os moradores locais se colocam diante de uma nova atividade econômica e da circulação de pessoas estranhas ao seu entorno de moradia. Ou seja, a existência de atrativos naturais é um fator importante de atratividade, mas sem as desejáveis condições de alojamento, transporte e alimentação tendem a transformar o local em algo pouco acessível e procurado somente por alguns segmentos dispostos a conhecer sítio, independente das dificuldades e inacessibilidade do entorno (BRAGA; GONTIJO; VIEIRA, 2015, p. 690).

Meliani (2012), por sua vez, analisou a estrutura e a distribuição espacial do trabalho formal e informal no turismo do Brasil, a partir de estimativas de ocupados, formais e informais, feitas pelo Instituto de Pesquisa Econômica Aplicada (IPEA). Argumentando que o turismo é uma atividade importante devido a sua elevada capacidade de criação de empregos, o autor questiona, no entanto, como este potencial tem sido aproveitado no contexto brasileiro, uma vez que há um elevado grau de 
precarização que prevalece nas relações de trabalho e na prestação de serviços turísticos. Em seus achados, o autor observa que:

Apesar de possuir mais da metade dos trabalhadores formais do país, o Sudeste apresenta uma taxa de informalidade regional (51,6\% do Sudeste, 422.456 informais) tão significativa quanto às outras regiões brasileiras. No Sul e no Centro-Oeste, a quantidade de trabalhadores informais ficou em torno de $50 \%$, enquanto que no Norte e no Nordeste a situação se acentua, com as taxas de informalidade no trabalho ultrapassando os $70 \%(71,74 \%$ no Nordeste e $74,1 \%$ no Norte). Apesar das acentuadas diferenças regionais em termos de ocupações totais, observamos que a participação dos informais é superior à participação dos formais em todas as regiões brasileiras. Os serviços de "Transportes", "Alimentação" e "Alojamento" são os que, em termos nacionais, empregam o maior contingente de trabalhadores. Todavia, apenas nos serviços de "Alojamento" e de "Aluguel de Transportes" é que as taxas de formalidade no emprego são superiores a $50 \%$ (MELIANI, 2012, p. 477).

O autor sugere que, de posse da análise espacial empreendida, é possível realizar, por parte dos governantes, ações para modificar o perfil da distribuição espacial do emprego no Brasil, bem como criar mecanismos para a adoção de empregos formais.

Em uma perspectiva simbólica, alguns estudos tematizaram a análise espacial das atividades, focando sua discussão nos efeitos da localização e suas consequências sociais e em termos de políticas públicas. Um exemplo é apresentado por Silva e Dias (2010, p. 44), que analisaram a distribuição espacial dos hotéis ao longo período de 1889 a 1930 (Primeira República) e chamam a atenção particularmente para a influência desses espaços na formação de um imaginário moderno e de uma nova sociabilidade das classes médias altas e da elite local soteropolitana, uma vez que houve a reapropriação desses espaços, originalmente voltadas a prestação de serviços de hospedagem, para o uso para fins diversos, como bailes, encontros sociais e reuniões de negócios da elite local, que buscava projetar uma nova imagem mais associada a à modernidade e, portanto, descolada da imagem do Império.

Sotratti (2014), a partir do caso empírico da requalificação urbana do Rio de Janeiro para os grandes eventos da Copa do Mundo (2014) e dos Jogos Olímpicos (2016), faz uma reflexão sobre a refuncionalização urbana do centro da cidade a partir de projetos de intervenção urbana de grande impacto - em geral associados com grandes investimentos de capital nacional ou estrangeiro - bem como das transformações e consequências da implantação de tais propostas e seu impacto sobre a dinâmica da totalidade e da integração com a cidade, bem como o papel do turismo como vetor de desenvolvimento local. Segundo Sotratti (2014, p. 51), “os efeitos perversos da redução narrativa, praticado pelas políticas e ações do planejamento urbano e turístico consiste, sobretudo, na eficácia desses programas e na velocidade em que tais intervenções são incorporadas pelo imaginário dos turistas e moradores." 
Assim, considerando os estudos precedentes é possível, sobretudo no contexto brasileiro, identificar lacunas em termos de análises focadas em um sistema turístico e seus componentes principais, que ainda representam um campo em aberto, ao que se pretende dedicar neste trabalho.

\section{Metodologia}

Para realizar a análise espacial do sistema turístico procedeu-se metodologicamente a realização de um estudo de caso (YIN, 1984[2000]), tomando como locus de aplicação e levantamento de dados em um destino turístico único, a cidade de Juiz de Fora (MG).

Para tanto, inicialmente realizou-se o levantamento de informações relativas ao sistema turístico da cidade e seus componentes. Este estudo beneficiou-se do levantamento prévio de dados concernentes ao estudo do sistema turístico da cidade de Juiz de Fora, que teve como enfoque o exame sobre sua cadeia produtiva, realizado em 2016, onde foi possível identificar os principais elos componentes daquele sistema (PIMENTEL, 2020) com base no status de sua organização formal.

O banco de dados foi cotejado e atualizado, segundo informações disponíveis junto aos órgãos oficiais de turismo da prefeitura municipal de Juiz de Fora (https://www.pjf.mg.gov.br/turismo/index.php), gerando informações sobre oferta de equipamentos e serviços turísticos na cidade com base em seus principais elementos. Ao final, foram mapeados 588 pontos assim distribuídos: 146 atrativos; 228 restaurantes; 63 meios de hospedagem; 41 agências de viagem; 4 operadoras; 4 casas de câmbio; 14 equipamentos turísticos de eventos; 11 locadoras de veículos; 15 organizações sociais ligadas ao setor turístico; 20 empresas de transporte rodoviário; 10 pontos de transporte aeroviário; 11 equipamentos de apoio infra estrutura geral; 21 equipamentos de saúde.

O banco de dados foi então atualizado com os códigos de endereçamento postal de cada (CEP) estabelecimento, para capturar a posição geográfica dos equipamentos. Isto se deu por meio de buscas em sítios eletrônicos, para verificação, atualização e complementação de dados relativos aos estabelecimentos, bem como, para a obtenção de seus respectivos endereços - necessários em um segundo momento - ao processo de geolocalização. Uma vez que não foi possível obter as informações relativas a todos os spots mapeados, este processo foi complementado com o georreferenciamento in locu no caso de atrativos e equipamentos cujos endereços não se encontravam disponíveis, compondo finalmente a amostra analisada.

$\mathrm{Na}$ sequência, no tocante aos procedimentos e técnicas empregadas, para projeção cartográfica e análise da dinâmica espacial, recorreu-se ao uso de métodos geográficos, em particular de técnicas cartografia de geolocalização e georreferenciamento de spots relativos ao sistema turístico supramencionado, produzindo uma série de mapas temáticos: a) atrativos turísticos; b) meios de hospedagem; c) meios de alimentação; d) infraestrutura de apoio turístico; e) infraestrutura de apoio geral. 
Para representar e analisar visualmente a distribuição espacial de cada estabelecimento existente, utilizou-se o software QGIS, mais precisamente, do plugin MMQGIS, o qual permitiu geocodificar os endereços obtidos através de uma planilha elaborada no software Excel, em formato CSV, com a codificação UTF-8. O levantamento dos dados cartográficos consistiu na busca de arquivos no formato shapefile (inicialmente obtidos junto à Prefeitura de Juiz de Fora) e de imagens de satélite disponíveis que abrange a área de estudo. Cabe ressaltar, que todos os dados foram separados, organizados, sistematizados, editados e estruturados no sistema de coordenadas Geográfica, Sistema Geodésico Sirgas 2000 e Zona 23 Sul.

Com a finalização deste processo, iniciou-se, portanto, a elaboração dos produtos cartográficos inerentes à oferta de atrativos turísticos existentes em cada Região Urbana (RU) presente nas Regiões de Planejamento da cidade de Juiz de Fora. A partir dos produtos cartográficos e, da interpretação espacial desse mapeamento, foram determinados os valores percentuais (\%) da oferta de serviços turísticos presente em cada Região de Planejamento, segundo o plano diretor municipal vigente. A opção por tal classificação é justificada pela intenção de manter a consistência em relação ao modo pelo qual as diferentes áreas urbanas são zoneadas, o que lhes aplica, segundo a legislação vigente, determinadas restrições em termos de uso e ocupação do solo, por exemplo, no tocante ao número máximo andares que uma edificação (por exemplo, um hotel) pode ter.

Finalmente, de posse dos produtos cartográficos, organizamos a distribuição espacial do sistema turístico com base em três princípios: (1) a partir das regiões de planejamento urbano do município; (2) segundo mapas temáticos por subsetor -a) atrativos turísticos; b) meios de hospedagem; c) meios de alimentação; d) infraestrutura de apoio turístico; e) infraestrutura de apoio geral-, e por fim (3) a partir dos tipos de equipamentos da oferta existente, sendo este tipo, ao final, considerado o mais recomendado, no caso em tela, para a análise espacial do sistema turístico representado devido a incidência representativa majoritária do fenômeno de forma funcional e sintética no mesmo campo visual. Outrossim, devido preponderantemente à densidade e grau de dispersão dos elementos do sistema turístico, a divisão administrativa municipal pode ser considerada marginalmente relevante para os propósitos da presente análise da distribuição espacial do fenômeno.

\section{Análise: Apresentação dos Resultados e Discussão}

\section{Contexto, Locus e Objeto de Estudo}

Juiz de Fora foi uma cidade marcadamente industrial e operária no início do século XX, vindo, posteriormente, a ser marcada pela força dos serviços. Atualmente o município se caracteriza como polo regional, sendo a $4^{\mathrm{a}}$ cidade mais populosa do estado de Minas Gerais e a mais populosa da Zona da Mata Mineira. Além de exercer forte influência sob a Zona da Mata Mineira - estendendo a cerca de 2,7 milhões de habitantes dos mais de 142 municípios que compõem esse território -, a cidade também 
polariza outras regiões administrativas do estado de Minas Gerais, a saber, a Mantiqueira e o Campo das Vertentes.

A polarização exercida por Juiz de Fora se manifesta em diferentes áreas da sociedade, podendo ser notada em aspectos econômicos, na prestação de serviços e também no setor de ensino. No que tange à perspectiva econômica, o município, responde pela metade da participação do PIB industrial e de serviços de sua região ${ }^{4}$.

O setor industrial reúne diversas empresas, incluindo as do ramo automobilístico, siderúrgico, químico, alimentício, vestuário e de bens intermediários, que se beneficiam de uma infraestrutura ${ }^{5}$ de alta qualidade e de posicionamento estratégico. Em termos de serviços oferecidos, Juiz de Fora é uma referência regional quanto ao sistema de saúde ${ }^{6}$ e quanto à oferta de serviços por órgãos públicos ${ }^{7}$. Ademais, o município também atrai os residentes da região em razão de seu setor comercial e de serviços em geral, que conferem uma dinâmica particular à vida da cidade, com alto grau de qualidade de vida e de desenvolvimento ${ }^{8}$.

Igualmente Juiz de Fora destaca-se também na área do ensino, pois possui em torno de 484 escolas, sendo 213 de nível pré-escolar, 209 de nível fundamental e 62 de nível médio (IBGE, 2016) ${ }^{9}$. No que tange à educação superior, Juiz de Fora conta com uma universidade federal - que possui atualmente cerca de 22.000 alunos $^{10}$ - , um Instituto Federal de Educação, Ciência e Tecnologia (IF Sudeste MG) e dez instituições

\footnotetext{
${ }^{4}$ De acordo com dados do IBGE (2016), enquanto o setor da indústria corresponde a R \$ 2.702 .832 do Produto Interno Bruto (PIB) do município, o setor de serviços representa R 7.369.350 do PIB. Em 2012, a atividade econômica da cidade alcançou, pela $1^{\mathrm{a}}$ vez na história, um Produto Interno Bruto superando a ordem de 10 bilhões de reais ( $\mathrm{R} \$ 10.048 .703,00)$, ficando em $5^{\circ}$ lugar do estado, com uma renda per capita equivalente a 19.188,73 (TRIBUNA DE MINAS, 2014; IBGE, 2012).

${ }^{5} \mathrm{~A}$ infraestrutura produtiva local provê às indústrias gás natural, acessibilidade por fibra ótica e facilidades logísticas por meio da estação aduaneira do interior. O Aeroporto Regional da Zona da Mata, que entrou em operação em 2011, apresenta a segunda maior pista do estado, com 2.525 metros, e serve à localidade nas modalidades de passageiros e cargas (PREFEITURA MUNICIPAL DE JUIZ DE FORA - PMJF, 2016).

${ }^{6}$ A cidade conta, atualmente, com 22 hospitais, mais de 2.600 leitos, mais de 2.300 médicos (PMJF, 2016) e 321 estabelecimentos de saúde (IBGE, 2016).

${ }^{7}$ Serviços de órgãos como a Receita Federal, a Procuradoria e a Justiça Federal, a Polícia Federal, o Ministério do Trabalho, a Previdência Social e congêneres.

${ }^{8}$ Cumpre ressaltar que Juiz de Fora é uma das cidades brasileiras com melhores índices de qualidade de vida em todo o Estado de Minas Gerais. A expectativa de vida é de 78,4 anos, uma das mais altas do Brasil (PLANO MUNICIPAL DE TURISMO, 2004). Já o seu índice de desenvolvimento humano (IDH) corresponde a 0,778 (valor considerado alto, em uma escala que apresenta os níveis "muito baixo", "baixo", "médio", "alto" e "muito alto"). Juiz de Fora ocupa a $7^{\mathrm{a}}$ posição entre as cidades com melhor qualidade de vida em Minas Gerais e a $145^{\mathrm{a}}$ no Brasil (PNUD, 2013).

9 Instituto Brasileiro de Geografia e Estatística - IBGE. Cidades @. Disponível em $<$ http://ibge.gov.br/cidadesat/painel/educacao.php?lang=\&codmun=313670\&search=minas-geraisjjuiz-defora|infograficos:-escolas-docentes-e-matriculas-por-nivel>. Acesso em 20 de dezembro de 2016.

${ }^{10}$ Universidade Federal de Juiz de Fora. Disponível em <http://www.ufjf.br/portal/universidade/ufjf/dadosestatisticos/ >. Acesso em 15 de dezembro de 2016.
} 
particulares ${ }^{11}$. A rede educacional do município apresentou, em 2012, 11.088 matrículas no ensino pré-escolar, 64.749 matrículas no ensino fundamental e 20.584 matrículas no ensino médio (IBGE, 2016). Há, na cidade, a oferta de mais de 50 cursos distintos de graduação, nas modalidades presencial e semipresencial, destacando-se, em particular, a mente a existência da Universidade Federal de Juiz de Fora (UFJF) ${ }^{12}$ no tocante aos serviços educacionais, uma vez que ela contribui para que a cidade se constitua como um verdadeiro polo educacional, atraindo estudantes de cidades do entorno, bem como de outros estados e regiões ${ }^{13}$.

Com relação ao turismo, a cidade de Juiz de Fora, além de toda a região da Zona da Mata, apresenta diversas oportunidades de atuação para o egresso do Mestrado em Turismo, uma vez que possui uma cadeia produtiva de turismo em desenvolvimento, com uma rede hoteleira e de restauração estabelecida, bem como agências de turismo tanto emissivas como receptivas, além de ter como principal vocação atualmente o turismo de negócios e eventos. A cidade (e região) conta, ainda, com um conjunto expressivo de patrimônios culturais, como a primeira usina hidroelétrica da América Latina, o Museu Mariano Procópio, possuidor do segundo maior acervo histórico do período imperial brasileiro (o primeiro se encontra no Museu de Petrópolis), fazendas centenárias, e com um relevante patrimônio natural, composto por serras, rios e cachoeiras, cafezais e alambiques, pelo Parque Estadual de Ibitipoca (localizado nas cidades de Lima Duarte e Santa Rita de Ibitipoca), pelo Parque Estadual do Brigadeiro (ocupa territórios de Araponga, Fervedouro, Miradouro, Ervália, Sericita, Pedra Bonita, Muriaé e Divino). Também é reconhecida pelos seus diversos eventos festivos e técnicocientíficos, pelas opções de entretenimento, e pela fabricação de cervejas artesanais, o que reforça a atuação do profissional egresso do Mestrado em Turismo na estruturação da oferta e do produto turístico local e regional.

${ }^{11}$ CES (Centro de Ensino Superior de JF); Doctum; Faculdade Estácio de Sá; Faculdade FJF; Faculdade Metodista Granbey; Faculdade Machado Sobrinho; Suprema; Unipac; Universo; Instituto Vianna Júnior.

${ }^{12}$ Criada em 23 de dezembro de 1960, atualmente a Universidade Federal de Juiz de Fora atende estudantes tanto em seu campus principal, na cidade de Juiz de Fora, como em seu campus estendido, no município de Governador Valadares, também em Minas Gerais. Através de suas ações, a UFJF vem se destacando como um dos principais centros de formação de recursos humanos e de geração de conhecimento, possuindo assim papel decisivo no desenvolvimento regional.

${ }^{13}$ Atualmente, mais de $60 \%$ dos estudantes da UFJF são provenientes de outras cidades e Estados (UFJF, 2017). 


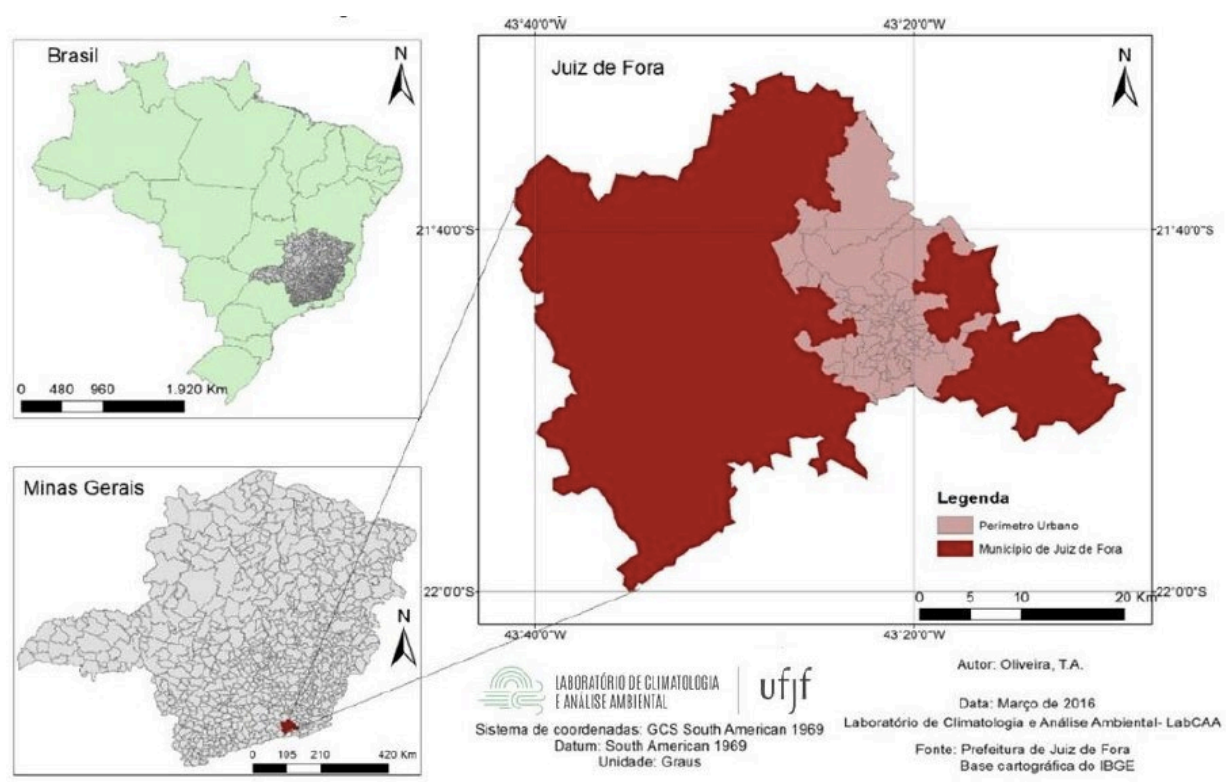

Figura 1: Mapa com a Localização de Juiz de Fora.

Fonte: reproduzido de Oliveira et al. (2019, p. 129).

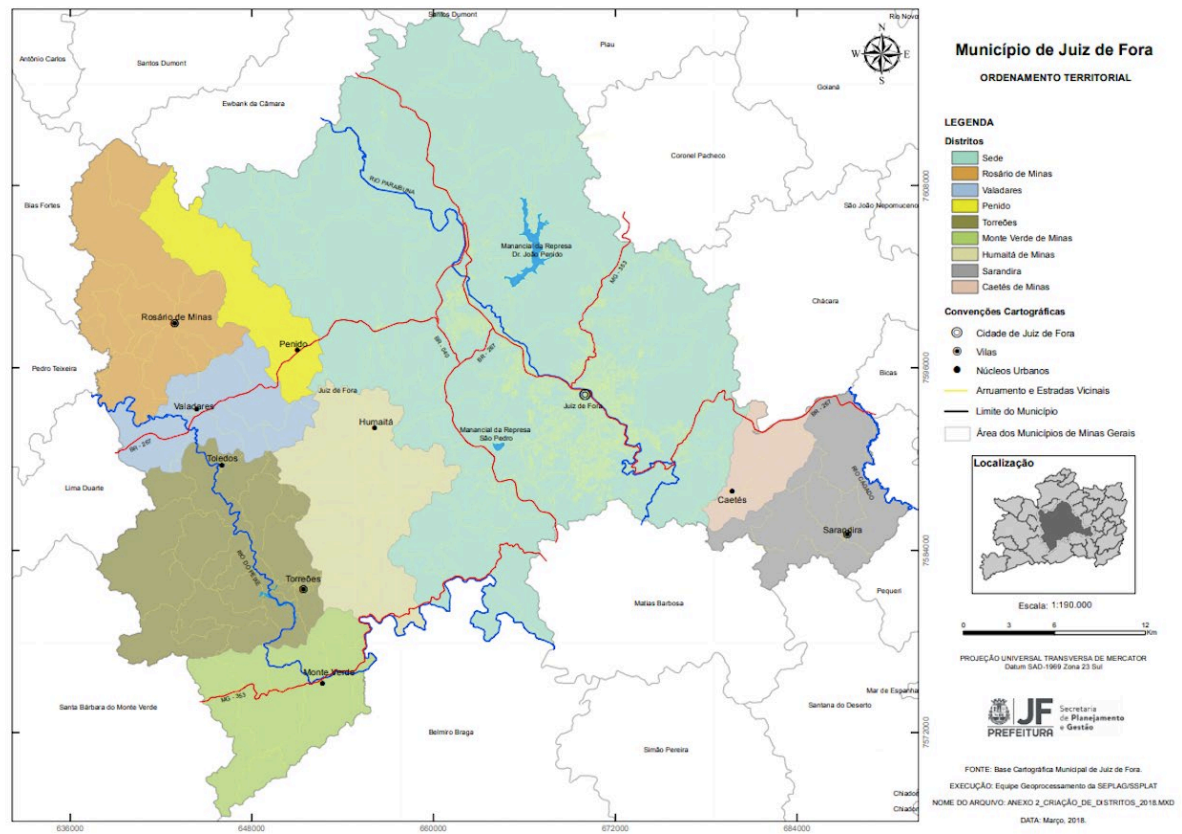

Figura 2: Município de Juiz de Fora, sede e demais regiões de ordenamento territorial. Fonte: Prefeitura Municipal de Juiz de Fora (2020). 


\section{Apresentação dos Resultados: Simulação da Análise Espacial por Critério Predominante de Classificação}

\section{Por Tipo de Equipamento do Sistema Turístico}

Neste conjunto de cartas optou-se por agrupar os dados por tipo de equipamento turístico e representar um mesmo tipo em todas as regiões administrativas da cidade. Devido a diversidade de elementos da oferta turística, optou-se pela elaboração de 5 tipos de mapas: atrativos, meios de hospedagem, alimentação, demais serviços turísticos e serviços de apoio geral, nestes dois últimos casos (unificando tipos de estabelecimento distintos com baixa incidência para justificarem uma carta temática própria).

No primeiro caso - mapa de atrativos turísticos (Figura 3) - observou-se a distribuição dos atrativos de forma assimétrica no destino turístico, com destaque para uma mais elevada concentração na região de administrativa de planejamento central, que concentra $58,9 \%$ dos 146 atrativos listados da oferta turística da cidade. Por esta razão, na seção seguinte será dado um enfoque específico a esta região. Em seguida, as regiões oeste ( 23 ou $14,4 \%$ ) e sul (15 ou 9,4\%) são as que concentram mais atrativos. As demais 5 regiões concentram menos de $15 \%$ dos atrativos da cidade.

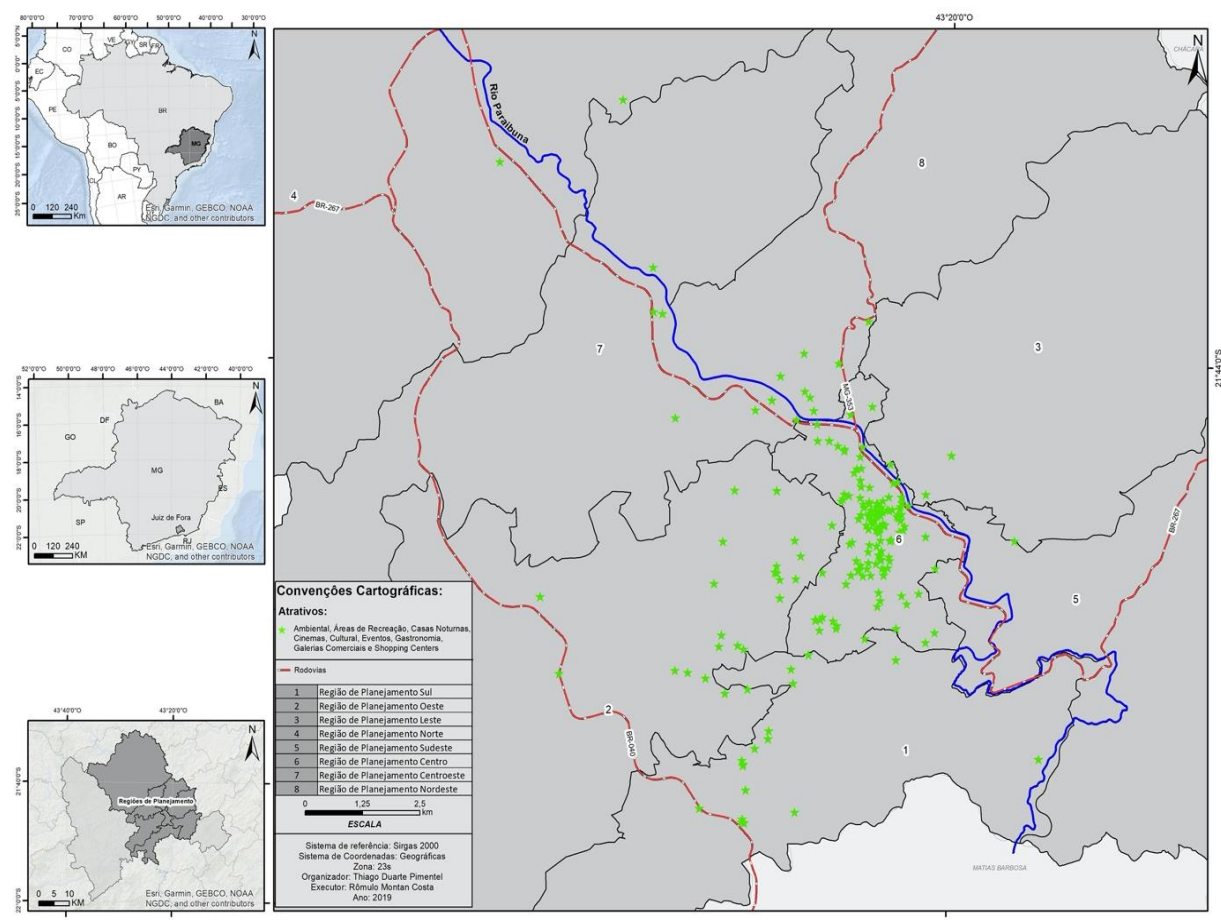

Figura 3: Distribuição espacial de atrativos em Juiz de Fora, em nível municipal.

Fonte: elaboração própria. 
A segunda carta temática elaborada foi a de estabelecimentos de alimentação, que contou com a localização de 228 equipamentos potencialmente turísticos. Igualmente em relação aos atrativos, pode-se observar a maciça concentração daquele tipo de equipamento na região central (179 ou 78,5\%), seguido apenas de uma parcela considerável na região oeste (22 ou 9,6\%). As demais regiões concentram menos de $12 \%$ deste tipo de oferta (Figura 4).

A terceira carta temática elaborada (Figura 5) foi a de meios de hospedagem. Dos 63 equipamentos identificados, $33(52,4 \%)$ estão na região central, $8(12,7 \%)$ na região sul e $6(9,5 \%)$ na região oeste, regiões estas que concentram $74,6 \%$ destes equipamentos.

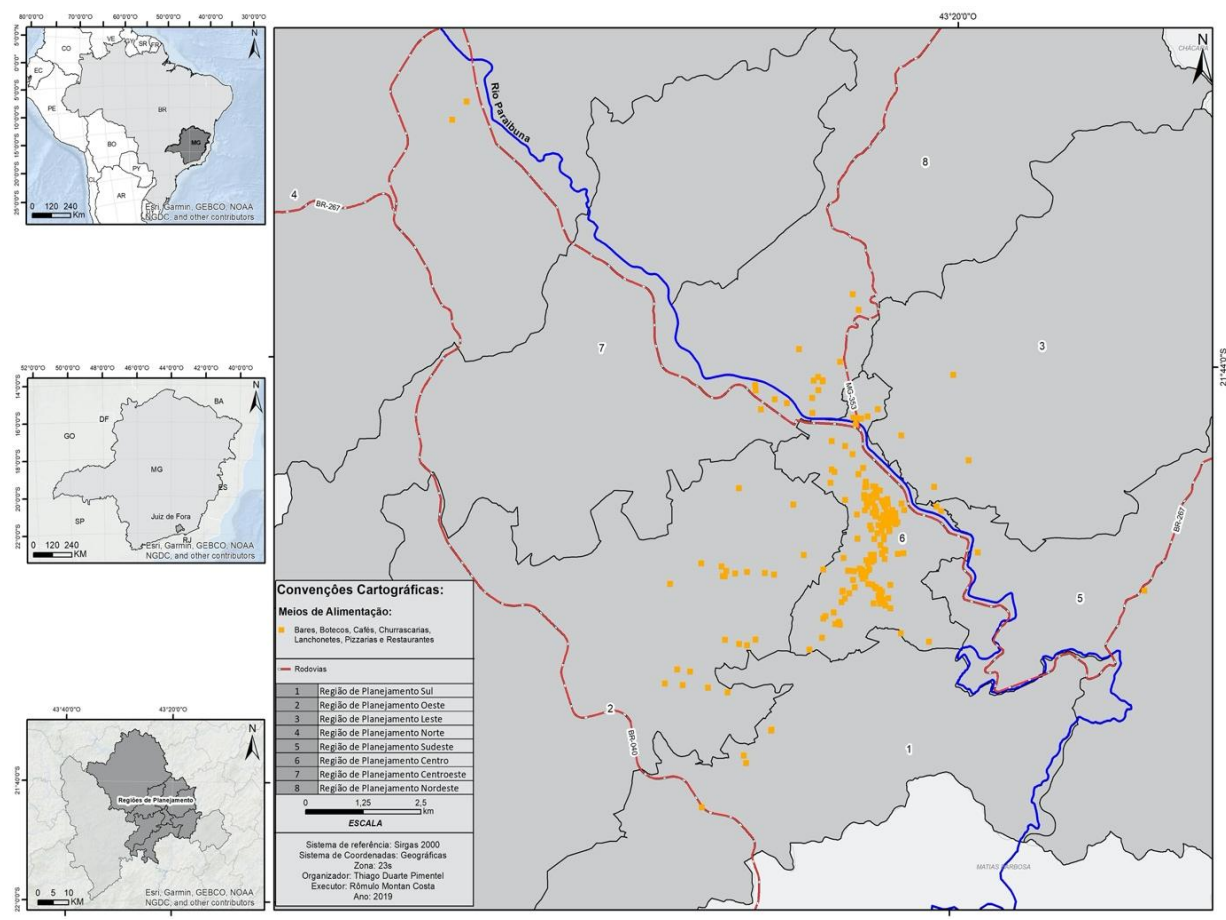

Figura 4: Distribuição espacial de meios de alimentação em Juiz de Fora, em nível municipal. Fonte: elaboração própria. 


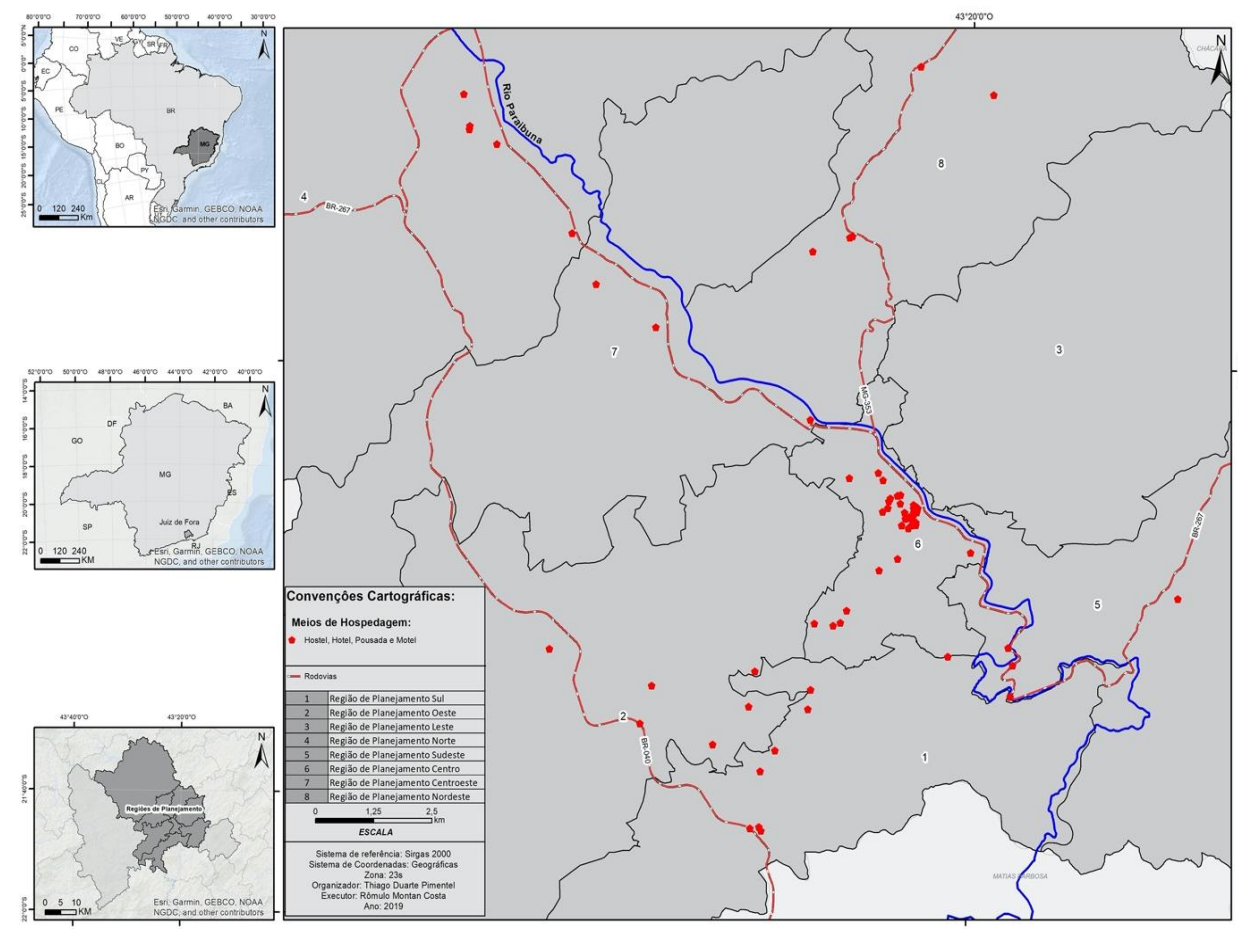

Figura 5: Distribuição espacial de meios de hospedagem em Juiz de Fora, em nível municipal. Fonte: elaboração própria.

Ainda foi elaborada uma quarta carta temática sobre a infraestrutura de apoio turístico (Figura 6), que agregou os demais elementos da oferta turística citadas na metodologia. A distribuição dos 74 itens se deu com aqui agregados se deu $59(79,7 \%)$ dos componentes na região central, $4(5,4 \%)$ na região oeste, $4(5,4 \%)$, na região centro oeste, $3(4,0 \%)$ na região sul e $2(2,7 \%)$ na região sudeste e $2(2,7 \%)$ na região nordeste. 


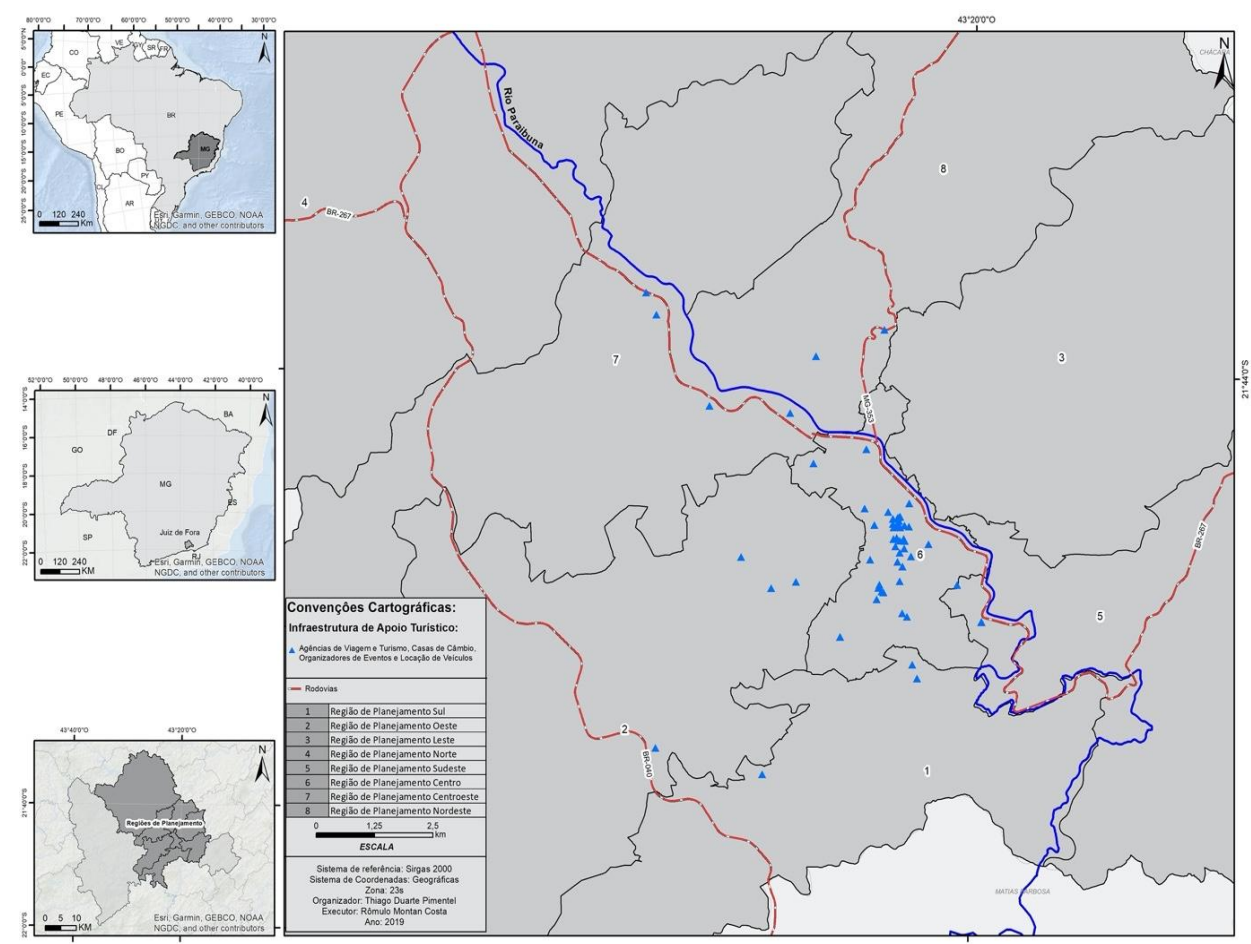

Figura 6: Distribuição espacial de infraestrutura de apoio turístico em Juiz de Fora, em nível municipal.

Fonte: elaboração própria.

Por último, os 77 equipamentos agrupados como elementos de infraestrutura de apoio geral apresentaram uma distribuição com $50(64,9 \%)$ localizados na região central, $8(10,4 \%)$ na centro oeste, $7(9 \%)$ na região oeste, $3(3,8 \%)$ na região sul, $3(3,8 \%)$ na sudeste, $3(3,8 \%)$ na norte, $2(2,6 \%)$ na nordeste, e $1(1,3 \%)$ na leste (Figura 7$)$. 


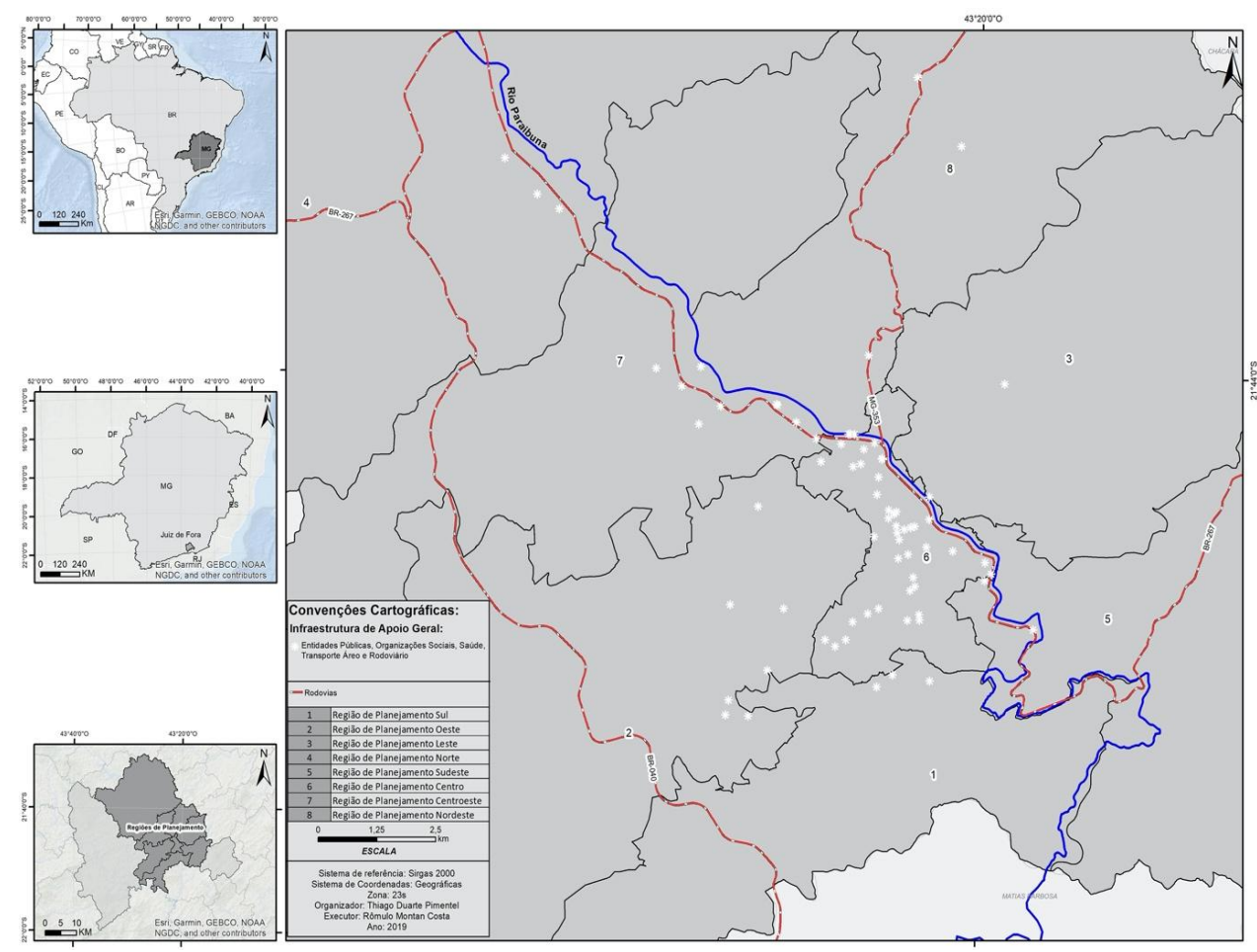

Figura 7: Distribuição espacial de infraestrutura de apoio geral em Juiz de Fora, em nível municipal.

Fonte: elaboração própria.

A carta representada como Figura 8 sobrepõe no mesmo plano todas as camadas com atributos temáticos que foram analisados em separado previamente. Nela se pode constatar, e forma inequívoca, a concentração da oferta turística (para todos os tipos de equipamentos analisados, inclusive atrativos) na região central da cidade de Juiz de Fora, com franjas de atividade nas regiões oeste e sul, onde há equipamentos de restauração e atrativos no primeiro caso e equipamentos de eventos e entretenimento (sobretudo noturno) no segundo. 


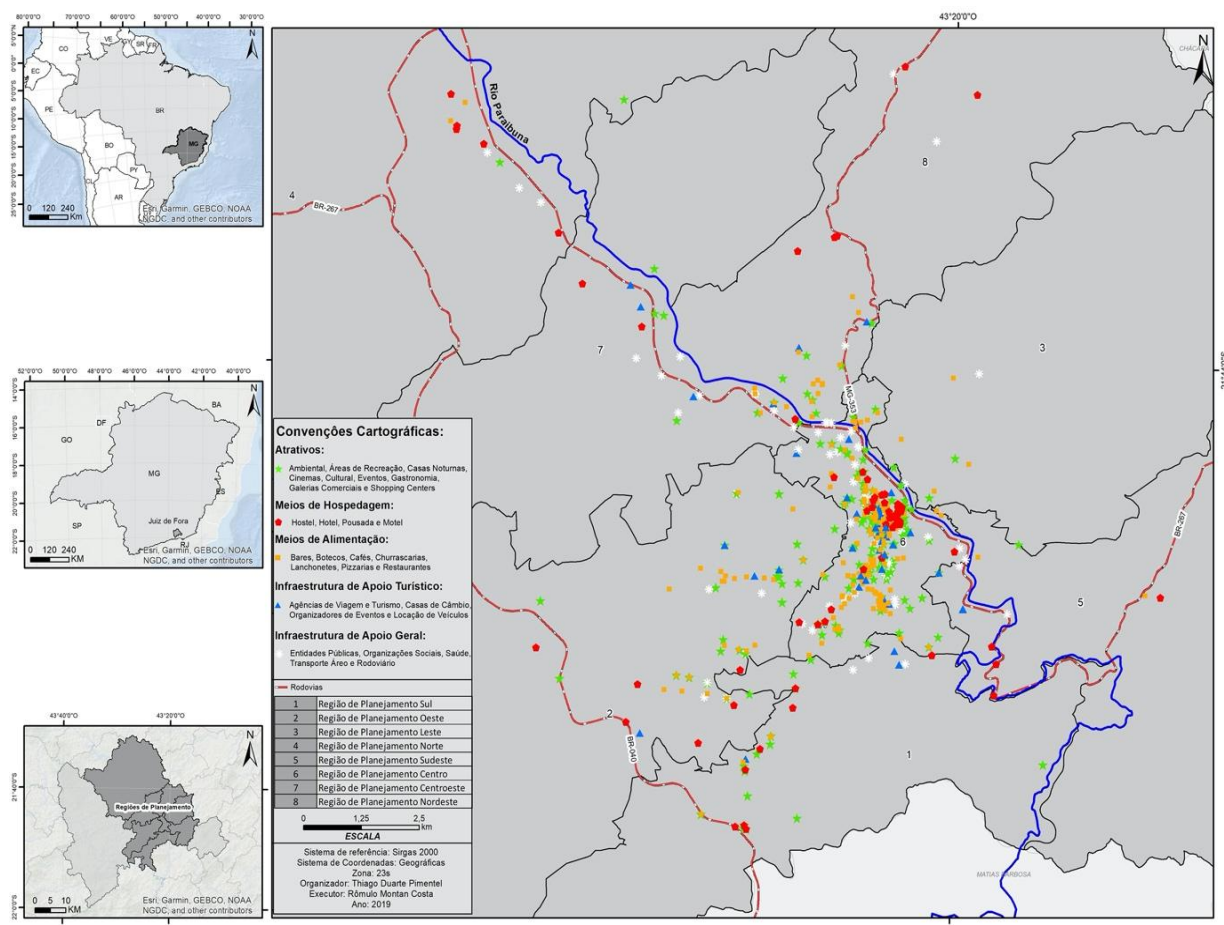

Figura 8: Distribuição espacial da oferta turística em Juiz de Fora, em nível municipal. Fonte: elaboração própria.

\section{Por Centralidade (Concentração Espacial e Incidência do Fenômeno)}

Neste conjunto de cartas optou-se por analisar em detalhe a região de planejamento central do município devido a importância relativa que a mesma apresentou na análise precedente no tocante a concentração da oferta turística. Igualmente, e para efeitos de comparação, optou-se pela elaboração de 5 tipos de cartas: atrativos, meios de hospedagem, alimentação, demais serviços turísticos e serviços de apoio geral, nestes dois últimos casos (unificando tipos de estabelecimento distintos com baixa incidência para justificarem uma carta temática própria).

No primeiro caso - mapa de atrativos turísticos (Figura 9) - observou-se além da distribuição geral do número de atrativos, os tipos predominantes, a saber: 20 elementos identificados como atrativos de compras e lazer (galerias, shoppings e cinemas), 31 atrativos culturais, 11 relacionados à recreação e lazer, 7 a gastronomia e eventos, 3 atrativos naturais e 2 casas noturnas. Em que pese a maior oferta de atrativos culturais, de compras e de recreação e lazer; tal oferta de atrativos mostra-se diversificada, merecendo destaque inclusive para áreas verdes (como o Parque Halfeld e o mirante do Morro do Cristo) o que é incomum nas áreas centrais de cidade mais populosas. Em síntese, em termos de atrativos, há 74 (52\%) atrativos num raio de cerca 
de $1 \mathrm{~km}$, o que sugere uma oportunidade de ser explorada na integração e conversão de parte destes atrativos em produtos turísticos.

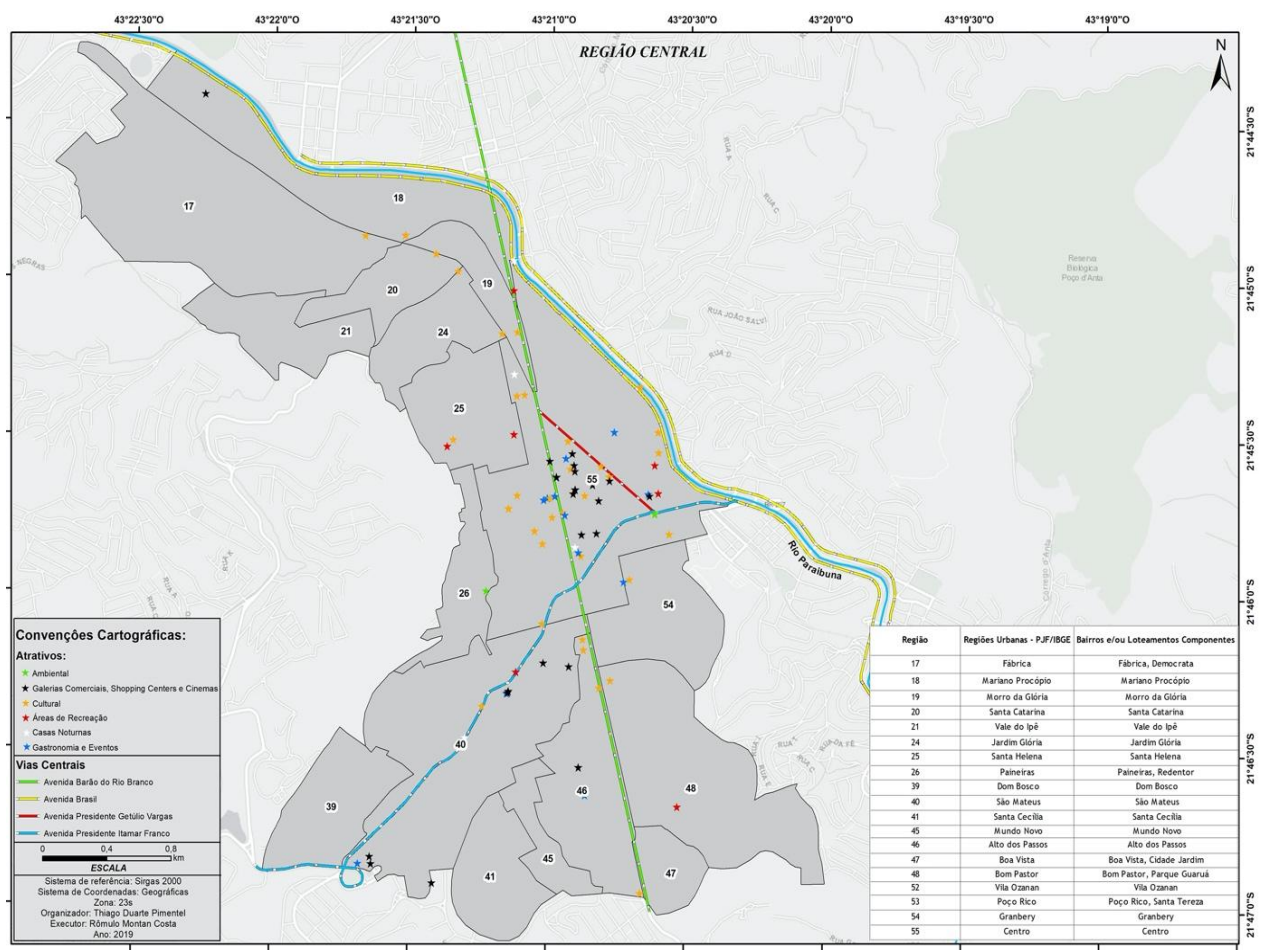

Figura 9: Distribuição espacial de atrativos em Juiz de Fora, nível região central. Fonte: elaboração própria.

Quanto aos estabelecimentos de alimentação (Figura 10), foi possível observar 54 cafés e lanchonetes, 47 restaurantes, 31 bares e botecos, perfazendo um total de 132 $(57,9 \%)$ dos 228 equipamentos potencialmente turísticos num raio de cerca de $1 \mathrm{~km}$. 


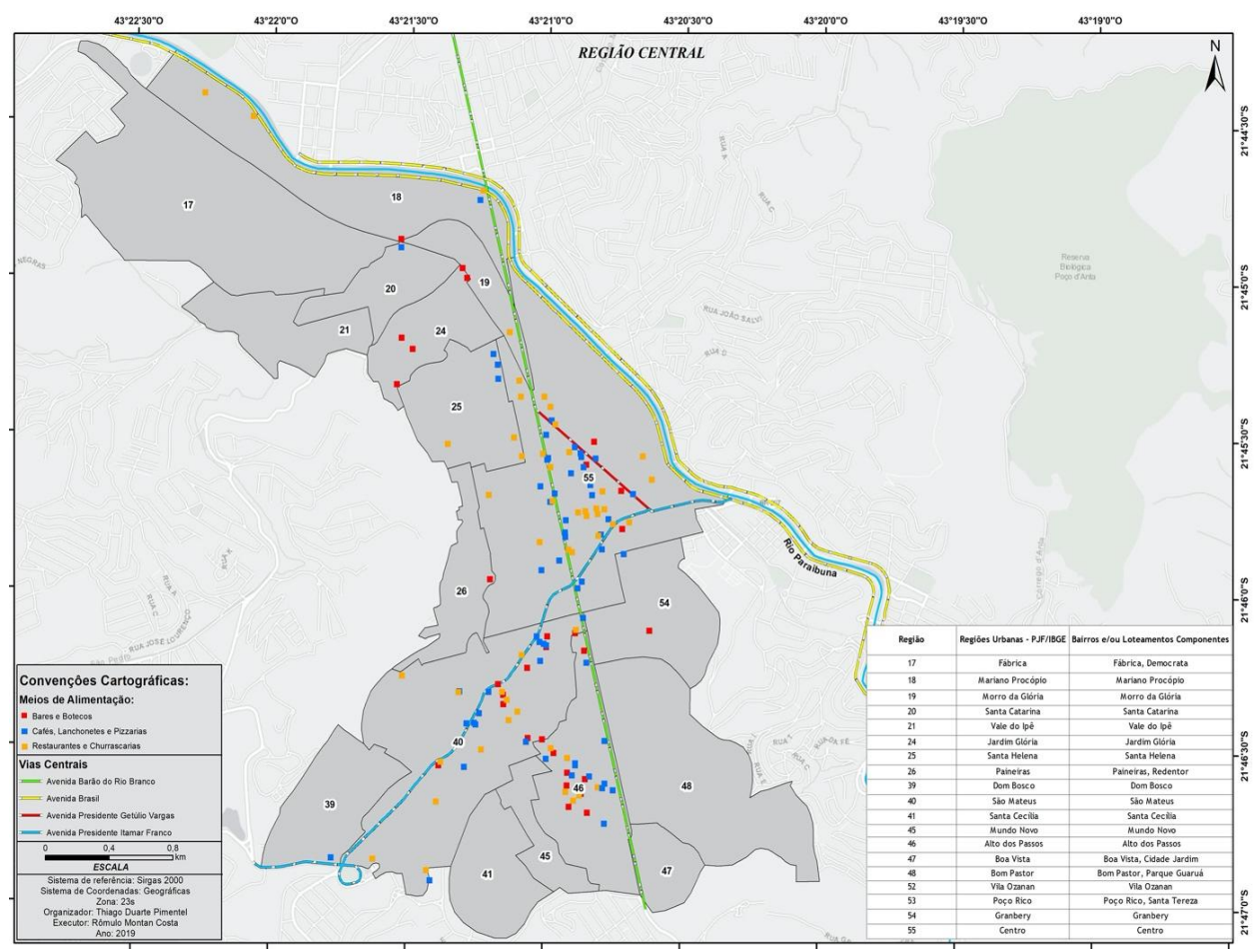

Figura 10: Distribuição espacial de meios de alimentação em Juiz de Fora, nível região central. Fonte: elaboração própria.

Com relação a distribuição de hotéis na região central da cidade (Figura 11), observou-se que dos $33(52,4 \%)$ de equipamentos identificados na região central, há 1 pousada, 2 hostels (albergues) e 30 hotéis. Ainda vale ressaltar que maciçamente, ou seja 22 (66\% daqueles instalados na região central e $34 \%$ do total de hotéis) dos hotéis se concentram no hipercentro da cidade, mais precisamente entre as avenidas cardeais (av. Rio Branco, av. Getúlio Vargas e av. Itamar Franco), num raio de menos de 500m entre si. 


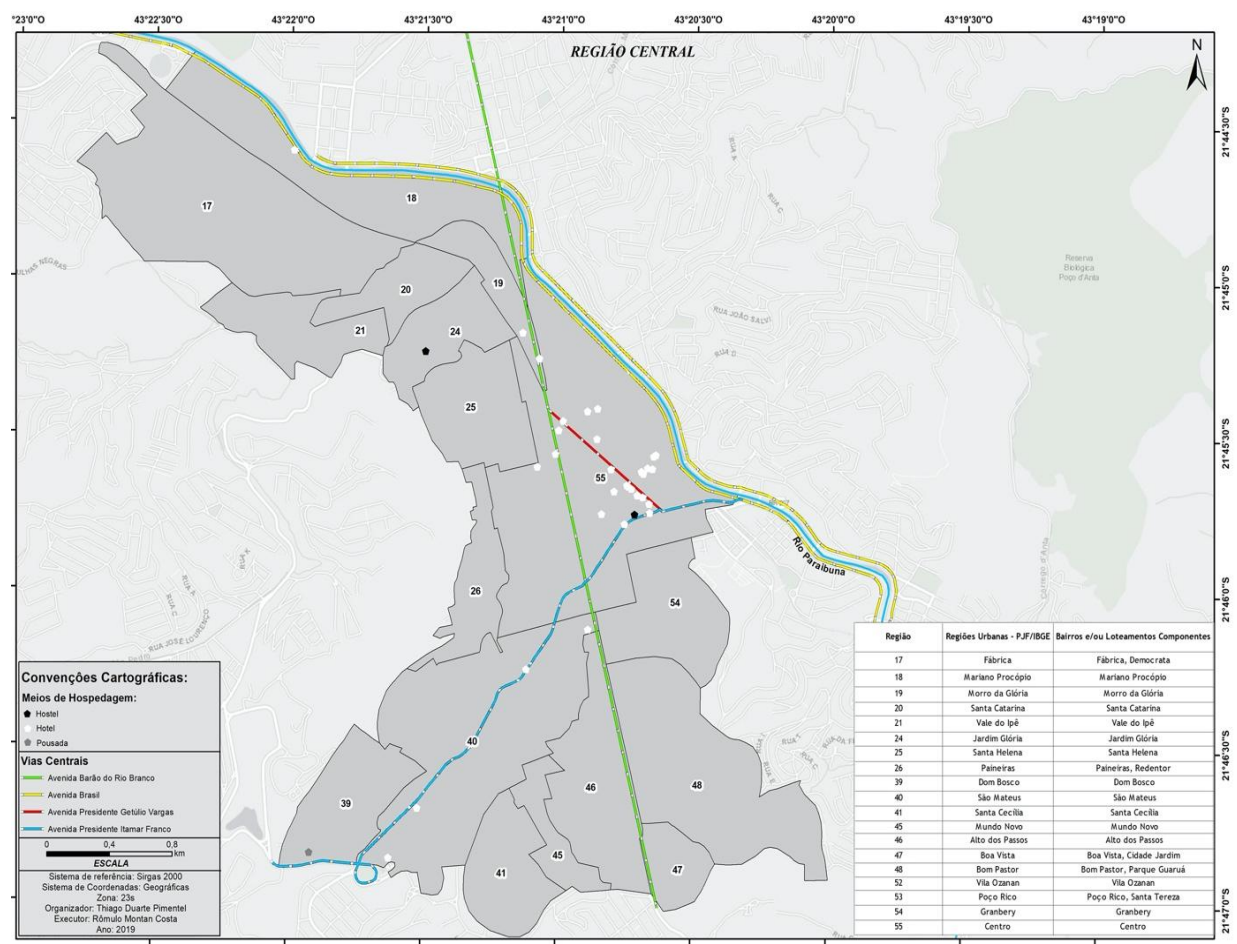

Figura 11: Distribuição espacial de meios de hospedagem em Juiz de Fora, nível região central. Fonte: elaboração própria.

Com relação a infraestrutura de apoio turístico da região central (Figura 12), dos 59 (79,7\%) componentes aí identificados, 19 agências estão no hipercentro (bairro 55), aí também aparecendo em segundo lugar equipamentos de eventos, locadoras de veículos e casas de câmbio. 


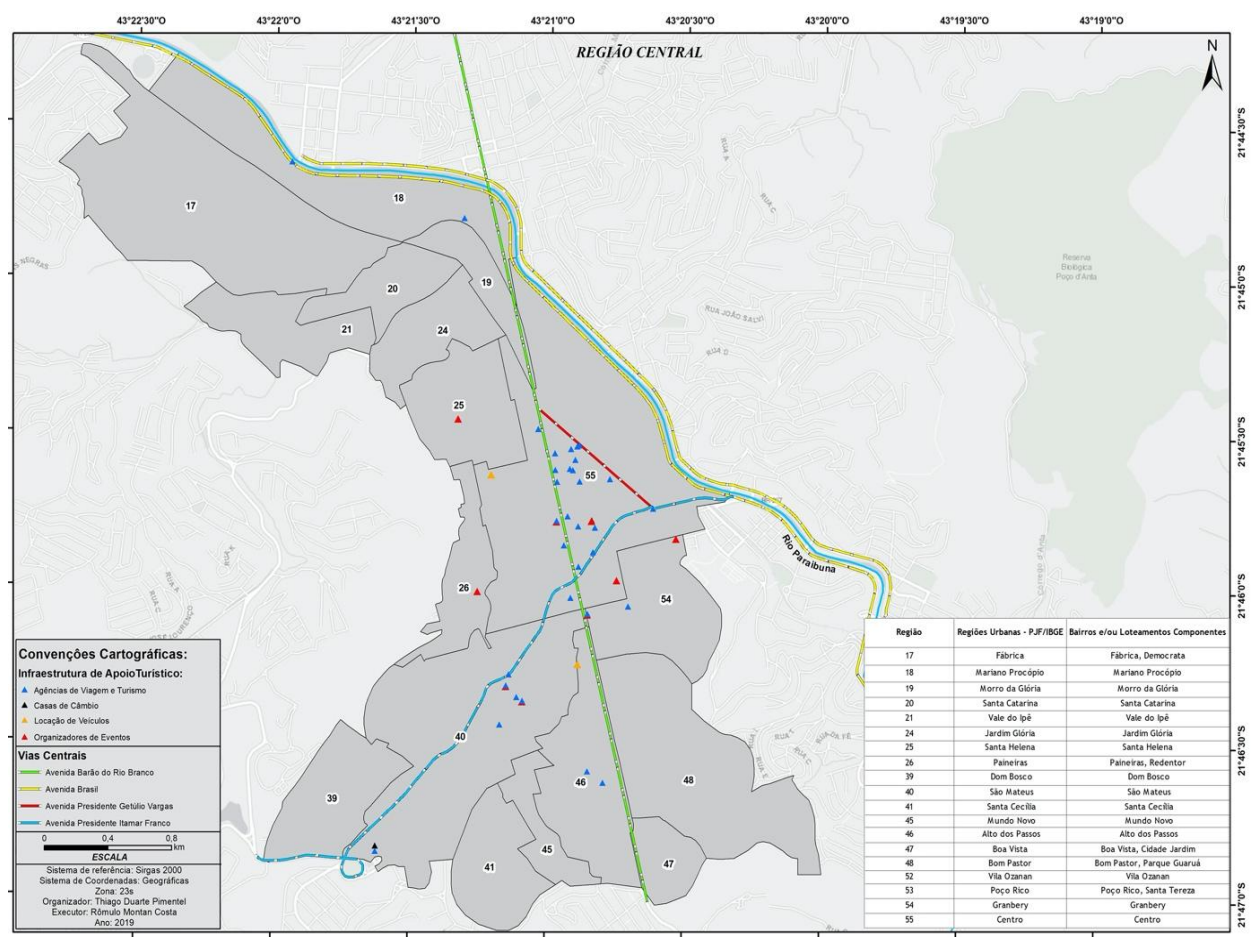

Figura 12: Distribuição espacial de infraestrutura de apoio turístico em Juiz de Fora, nível região central.

Fonte: elaboração própria.

Por último, dos $50(64,9 \%)$ elementos de infraestrutura de apoio geral localizados na região central (Figura 13), observa-se também a localização concentrada, mesmo na região central, de 7 equipamentos públicos, 4 organizações sociais, 2 de transporte aéreo, 1 de transporte rodoviário e equipamento de saúde. 


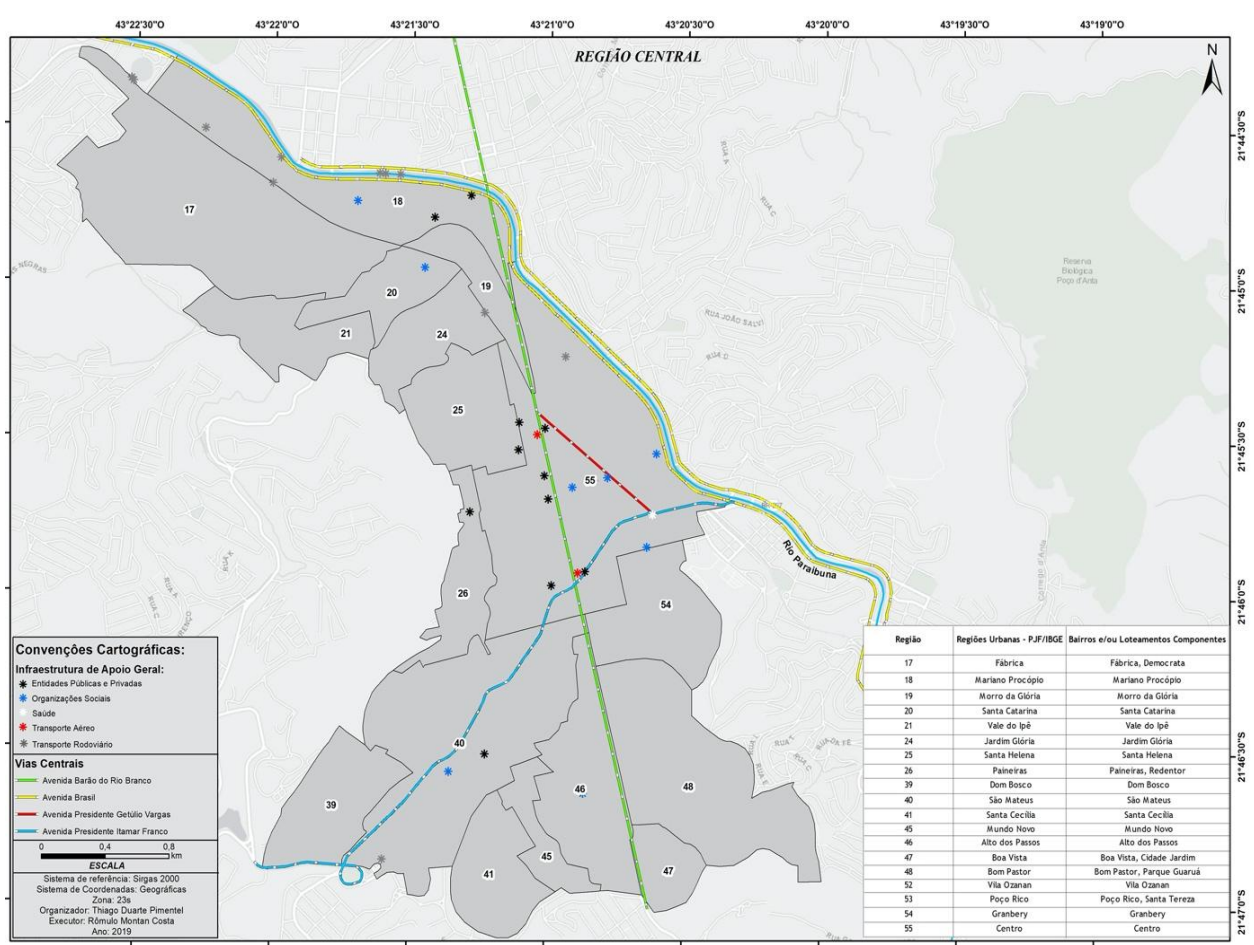

Figura 13: Distribuição espacial de infraestrutura de apoio geral em Juiz de Fora, nível região central.

Fonte: elaboração própria.

A carta representada como Figura 14 sobrepõe no mesmo plano todas as camadas com atributos temáticos que foram analisados em separado previamente. Nela se pode constatar, e forma inequívoca, a concentração da oferta turística (para todos os tipos de equipamentos analisados, inclusive atrativos) na região central da cidade de Juiz de Fora, com franjas de atividade nas regiões oeste e sul, onde há equipamentos de restauração e atrativos no primeiro caso e equipamentos de eventos e entretenimento (sobretudo noturno) no segundo. 


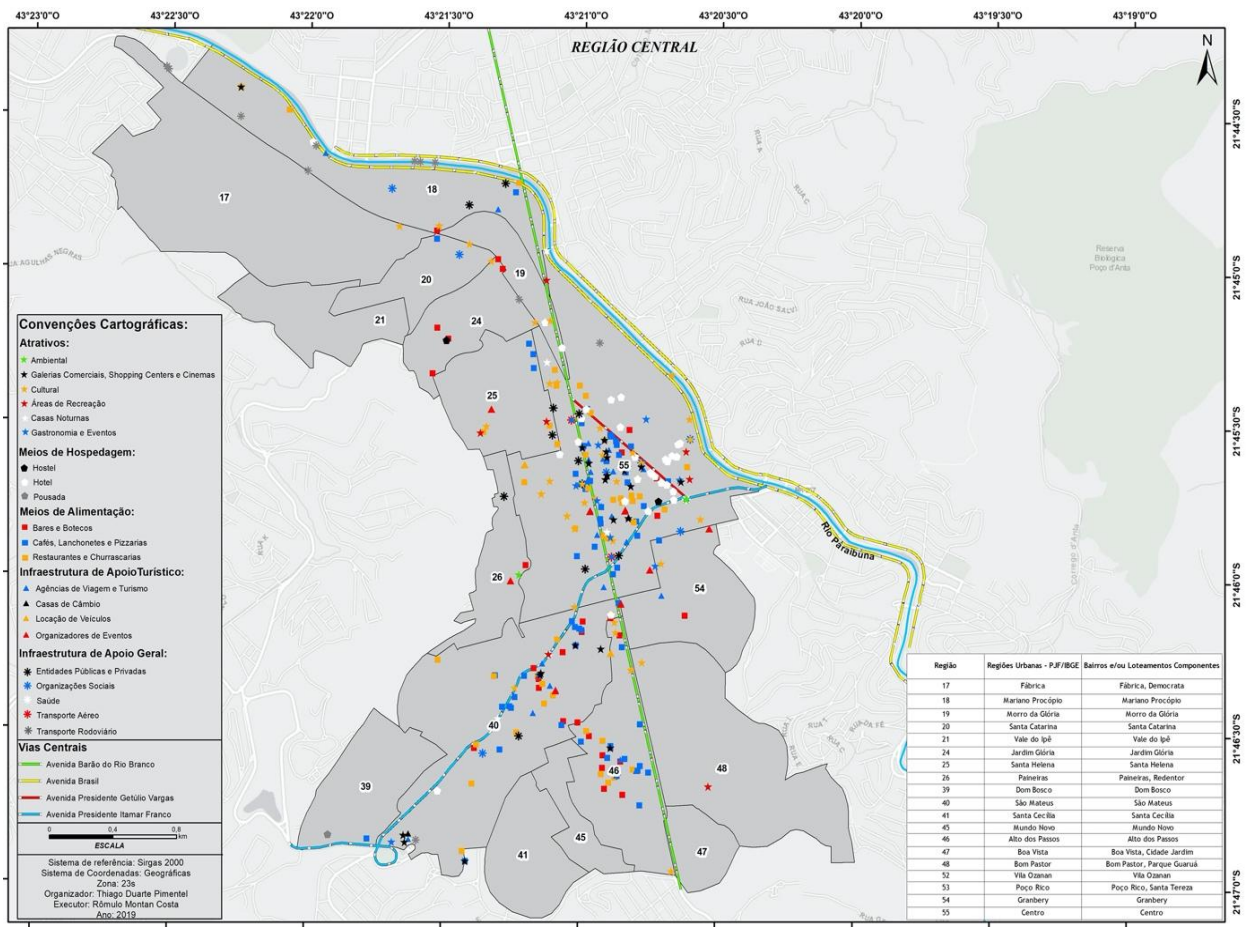

Figura 14: Distribuição espacial da oferta turístico em Juiz de Fora, nível região central Fonte: elaboração própria.

\section{Síntese, Comparação e Interpretação}

Os dados levantados foram analisados a partir de 4 categorias tal como apresentado no quadro 1 (Costa \& Souto-Maior, 2006), a saber: (1) localização, com atributo de proximidade e/ou concentração geográfica, (2) a identificação de atores sociais presença de organizações, públicas, privadas ou do terceiro setor, (3) a identificação de características comuns entre as organizações (i. especialização, misto de cooperação e competição entre as empresas, ii. cooperação entre empresas e instituições de interesse público, iii. canais de comunicação e confiança entre firmas, iv. identidade cultural entre atores sociais, v. relações econômicas e sociais), e (4) resultados esperados (i. redução de custos de transação e ii. capital social, crescimento e competitividade, iii. desenvolvimento local sustentável e equilibrado).

Baseado na interpretação dos produtos cartográficos, no caso em tela, observamos as duas características alusivas ao atributo localização: a) concentração, uma vez que foi identificado um predomínio absoluto da oferta de atrativos turísticos na Região Central da cidade de Juiz de Fora, representando $66 \%$ de todos os dados obtidos; e b) proximidade, uma vez que detecta-se a presença de cerca de $40 \%$ dos equipamentos turísticos e de suporte turísticos num raio de cerca de $500 \mathrm{~m}$ a partir do triângulo do 
hipercentro da cidade (Avenida dos Andradas com Av. Francisco Bernardino, Av. Rio Branco com Av. Presidente Itamar Franco, e Av. Francisco Bernardino com Av. Presidente Itamar Franco), o deste a o que confirma, tal como apresentado e sistematizado no quadro 1 , o atributo de localização dos componentes do sistema turístico (COSTA; SOUTO-MAIOR, 2006).

Foi possível também a (2) a identificação de atores sociais, em particular presença de organizações privadas de prestação de serviços turísticos, com destaque para a oferta de meios de hospedagem, e em segundo lugar a existência de organizações públicas, notadamente aquelas consideradas como atrativos turísticos, como museus, e centros culturais, e, em menor escala encontra-se também organizações do terceiro setor, como associações culturais (e.g. Casa d'Italia).

O predomínio da oferta de atrativos turísticos na Região Central da cidade justifica-se em virtude da presença de um forte núcleo comercial, bem como de atrativos histórico-culturais, tais como monumentos, museus, etc., que remontam historicamente à criação da cidade. Este cenário propiciou e continua a propiciar a concentração de uma grande variedade de atrativos turísticos, abrangendo, conforme mencionado anteriormente, as cinco categorias estabelecidas, com destaque para as categorias referentes aos Meios de Hospedagem (Hostel, Hotel e Pousada) e Alimentação (Bares, Botecos, Cafés, Lanchonetes, Restaurantes, Pizzarias e Churrascarias), os quais concentram-se, principalmente, nas RU`s Centro, Alto dos Passos e São Mateus.

Como a segunda região mais expressiva em termos de atrativos turísticos, temse a Região Oeste, a qual, nas últimas décadas, sobretudo, a partir da década de 60 e 70, com a construção da Avenida Presidente Itamar Franco, implantação do campus da Universidade Federal de Juiz de Fora, criação do aeroporto Francisco Álvares de Assis e da consolidação da rodovia BR-040 (PJF, 1996), tornou-se um dos principais vetores de crescimento da cidade. Tal conjuntura fomentou a instalação de diversos atrativos turísticos, sobretudo, conforme pode-se constatar a partir da elaboração dos produtos cartográficos, daqueles correlatos aos Meios de Alimentação (Bares, Botecos, Cafés, Lanchonetes, Restaurantes, Pizzarias e Churrascarias) e, Atrativos (Ambiental, Cultural, Área de Recreação e Casas Noturnas) e Meios de Hospedagem (Pousadas), os quais concentram-se, sobremaneira, nas RU`s de Martelos, São Pedro e Aeroporto.

Em terceiro plano, encontra-se a Região Sul, onde é possível perceber, sobretudo, nas RU`s Salvaterra, Santa Luzia, Ipiranga, Teixeiras e Graminha, o predomínio de atrativos turísticos vinculados aos Meios de Alimentação, Hospedagem e a Infraestrutura de Apoio Geral.

Nas demais regiões avaliadas, observa-se igualmente uma baixa distribuição de oferta turística em termos quantitativos. Ainda assim, há elementos pontuais que podem ser destacados em cada uma das regiões, como por exemplo, na região Leste há oferta de turística relacionada a estabelecimentos de Alimentação, sobretudo, no bairro de Manoel Honório; na Região Nordeste, há como destaque atrativos vinculados aos Meios de Alimentação e de ordem ambiental (presença da Mata do Krambeck e do Jardim 
Botânico da UFJF), particularmente no bairro de Santa Terezinha; já na Região Norte, além de alguns equipamentos de Alimentação, observam-se meios de Hospedagem (Hotel e Motel) e, daqueles inerentes a Infraestrutura de Apoio Turístico (Locação de Veículos) e Geral (Organizações Sociais, Transporte Rodoviário e Aéreo), os quais possuem ligação direta com a presença da BR-040. Por fim, com relação à Região Sudeste, não se verifica uma concentração de atrativos turísticos, mas, sim, uma dispersão dos mesmos ao longo do território de abrangência da região supramencionada. Destaca-se a presença pontual de Atrativos, Meio de Alimentação, Meios de Hospedagem e Infraestrutura de Apoio Turístico e Geral.

A identificação (3) de características comuns entre as organizações (COSTA; SOUTO-MAIOR, 2006) - tais como: i. especialização, misto de cooperação e competição entre as empresas, ii. cooperação entre empresas e instituições de interesse público, iii. canais de comunicação e confiança entre firmas, iv. identidade cultural entre atores sociais, v. relações econômicas e sociais - não foi o objeto de análise específica deste estudo, que se centrou no mapeamento do setor turístico da cidade. No entanto, devido a resultados de estudos anteriores, pode-se observar que "embora as empresas deste segmento [turístico] afirmem ser importante o estabelecimento de relações interorganizacionais, as mesmas, quando existem (cerca de um terço dos casos), se dão em nível incipiente, como "indicação" de empresa parceira e/ou compartilhamento de informação genérica/não estratégica" (PIMENTEL, 2019, p.17), o que sugere que as organizações mapeadas majoritariamente (1) não possuem relações entre si e (2) as que possuem os mantêm em nível superficial (predominando relações e canais de comunicação esparsamente utilizados e relações econômicas de fornecimento, onde 57\% das organizações analisadas dependem majoritariamente do(s) mesmo(s) fornecedore(s), mas apenas $41 \%$ dos fornecedores são de empresas locais, da própria cidade ou de cidades vizinhas.

Por fim, outro elemento importante no tocante às economias de aglomeração refere-se aos (4) resultados esperados (COSTA; SOUTO-MAIOR, 2006) - tais como: i. redução de custos de transação e ii. capital social, crescimento e competitividade, iii. desenvolvimento local sustentável e equilibrado-. Igualmente este dado não foi captado pelo presente estudo, uma vez que se ateve a dados secundários e de geolocalização. No entanto, conforme aponta Pimentel (no prelo, p. 22) "integração entre elos da cadeia com vistas a produzir sinergias, economias de escala e efeitos de catalizadores (por exemplo, por compras conjuntas dada o pequeno porte das empresas, aumento assim o poder de barganha). Em qualquer circunstância, entretanto, a cultura organizacional de "pequenos negócios cotidianos" que vê com desconfiança esse tipo de relacionamento precisa ser alterada com vistas e favorecer o compartilhamento de informações, visando alcançar, algum dia um estágio mais avançada de decisões conjuntas". A governança da cadeia de produtiva - via uma superestrutura organizacional coletiva - para propulsar tais direcionamentos, facilitar e integrar tomada de decisões, monitorar e gerir o sistema produtivo local com o fim de otimizar o desempenho da cadeia integralmente, seja pela redução de custos, pela adição de valor ou ambos, mas em qualquer cenário, um 
aumento de integração e mecanismos de controle se fazem necessários para otimizar o desempenho parece ser o maior desafio do sistema turístico local na atualidade.

\section{Conclusão}

Neste estudo realizamos uma análise espacial do sistema turístico de Juiz de Fora (MG). A partir do resgate das contribuições prévias, sobretudo da literatura nacional, sobre a localização espacial da oferta turística, pode-se perceber uma lacuna, em geral, neste tipo de estudo, e um gap específico em relação a estudos que especializam os componentes de um sistema turístico de forma integral. Realizamos tal ação por meio da elaboração de uma série de mapas que permitiu a visualização da incidência de 588 elementos da oferta turística previamente identificada e sua distribuição no espaço.

Considerando a análise dos spots com base em dois critérios - (1) por tipo de equipamento do sistema turístico; (2) por divisão da região de planejamento administrativa municipal (com destaque para a centralidade, i.e., a concentração espacial e incidência do fenômeno) - os resultados mostraram que, sob qualquer ângulo, há uma concentração espacial de atrativos $(58,8 \%)$, de equipamentos de alimentação $(78,5 \%)$, de hospedagem (52,4\%), de a infraestrutura de apoio turístico $(79,7 \%)$, e de infraestrutura de apoio geral $(64,9 \%)$ localizados na região central do destino. Mais especificamente, conferindo maior grau de detalhe nesta região, é possível observar ainda uma nova concentração na região administrativa 55 (bairro centro), que não se limita, mas, grosso modo, pode conformar o "triângulo central da cidade" (formado pelas Avenidas Barão do Rio Branco, Getúlio Vargas e Presidente Itamar Franco). Exclusivamente num raio de cerca de $500 \mathrm{~m}$ a partir do centro deste triângulo detecta-se a presença de cerca de $40 \%$ da oferta turística do sistema turístico em tela, considerando os seus diferentes elementos.

Se por um lado, esse grau de concentração pode ser considerado elevado, em termos de uma única região e ainda mais especificamente em um único bairro da cidade, por outro lado, isto pode facilitar a criação de produtos turísticos devido a diversidade de opções, a curta distância - tornando roteiros, por exemplo, passíveis de serem feitos a pé - e à integração com a infra estrutura de apoio turística e de serviços em geral.

Por fim, conclui-se, que para efeitos de planejamento e gestão do sistema turístico tais informações são relevantes pois permitem a visualização da distribuição da oferta existente, de forma funcional e sintética, apesar de suas múltiplas camadas, em um mesmo campo visual, sendo, portanto, um indicador de gestão potencialmente útil para tomada de decisões. Este estudo também pode ser potencialmente útil de forma prática, seja para órgãos públicos de gestão e controle da atividade (municipais e/ou estaduais), seja para a iniciativa privada, que poderá formatar novos produtos, roteiros e serviços em função de sua proximidade, afinidade e complementaridade - a serem ofertados no destino. 


\section{Referências}

BALSA-BARREIRO, J; LOIS-GONZÁLEZ, R.C. Particularidades y Estado Actual de la Cartografía Turística Oficial en Galicia. Cuadernos de Turismo, n. 26, p. 25-46, 2010.

BIZINELLI, C; MANOSSO, F.C; ABRAHÃO, C. M. S.; GÂNDARA, J.M.G. A Curitiba dos Restaurantes: Uma análise da evolução dos estabelecimentos de alimentação comercial com base nos registros do Guia Quatro Rodas - 1989/2014. Revista Hospitalidade. São Paulo, v. 13, 08-28, 2016.

BRAGA, S.S.; GONTIJO, B.M.; VIEIRA, L.M. A ação espacial do turismo: análise dos atrativos e equipamentos turísticos na Serra do Cipó (MG). Revista Brasileira de Ecoturismo, São Paulo, v. 7, n. 4, p. 681-693, 2015.

COSTA, H.; SOUTO-MAIOR, A. Sistemas produtivos locais em turismo: relacionamentos estratégicos e aglomeração territorial como vantagens competitivas. Observatório de Inovação do Turismo - Revista Acadêmica, v. I, n. 1, 2006.

CRUZ, R.C.A. Introdução à Geografia do Turismo. Segunda Edição. Editora Roca. 2003.

FERNANDES, D. L.; GOVEIA, E. F.; HORODYSKI, G. S.; GÂNDARA, J. M. G.

Marketing turístico do destino Paraná: atrativos, segmentos e sua distribuição no estado. Revista Anais Brasileiros de Estudos Turísticos - ABET, Juiz de For (Brasil), n. 2, v.2, p. 6578, 2012.

LASTRES, H. M. M.; CASSIOLATO, J. E. (2004). Políticas para promoção de arranjos produtivos inovativos locais de micro e pequenas empresas. Rede de Pesquisa em APL. RedeSist. Disponível em: www.ie.ufrj.br/redesist. Acesso em: 02/08/2013.

MARSHALL, A. Princípios de Economia. São Paulo: Abril Cultural. vol 1. 1982[1920].

MARTÍN, J.M.S.; RIVERO, M.S.; GALLEGO, J.I.R. Análisis del Equilibrio entre el Potencial Turístico y la Oferta de Alojamientos en Turismo Rural Mediante Técnicas de Estadística Espacial. Una Aplicación a la Provincia de Cáceres (España). Cuadernos de Turismo, n. 39, p. 547-576, 2017.

MELIANI, P.F. Estrutura e distribuição espacial do trabalho formal e informal no turismo do Brasil: contributos geográficos ao planejamento turístico regional brasileiro revista Turismo \& Desenvolvimento. v. 17/18, p. 467-478, 2012.

PEREIRA, C. C. de P.; GUIMARÃES, L. de O.; GOMES, M. A. (2011). Governança de Arranjos Produtivos Locais e Suas Possibilidades. Congresso da Associação Nacional de Pós-Graduação em Administração (ENANPAD). XXXV, 2011. Rio de Janeiro. Anais [...]. Rio de Janeiro: ANPAD, 2011, p. 1-15.

PERROUX, F. A Economia do Século XX. Lisboa: Herber, 1967.

PÍCCOLO, D.R.; GÂNDARA, J.M.G. Evolução da Distribuição Espacial dos Hotéis de Redes no Estado do Paraná (1940-2010). CULTUR, v. 07, n. 03, 2013. 
PIMENTEL, T. D. Análise do segmento de atrativos culturais da cadeia produtiva do turismo em Juiz e Fora (MG). Principia: Caminhos da Iniciação Científica, Juiz de Fora, v. 19, n. 1, 2019. DOI: https://doi.org/10.34019/2179-3700.2019.v19.30173

PIMENTEL, T. D. Análise Sistêmica da Cadeia Produtiva do Turismo de Juiz de Fora (Brasil). No prelo, 2021.

PIMENTEL, T. D. Mapeamento dos Centros de Pesquisa e da Oferta Educacional de Cursos de Turismo no Brasil e no Exterior: notas preliminares para delimitação do campo turístico mundial. Relatório de Pesquisa. Conselho Nacional de Desenvolvimento Científico e Tecnológico/CNPq e Pró-reitoria de Pesquisa da Universidade Federal de Juiz de Fora/PROPESQ-UFJF, Minas Gerais (MG), Brasil, 2016.

PIMENTEL, T. D.; CARVALHO, F. C. C. Distribution of Educational Offer and Tourism Research Centres: preliminary notes towards an academic tourism subfield in the world. In: 66 AIEST Annual Conference, 2016, Valletta, Malta. Proceedings.... Zurich, St Gallen (Switzerland): AIEST Press, 2016. v. 1. p. 1-1.

PIMENTEL, T.D.; BARBOSA, J.C.S.; CARVALHO, F.C.C. Modelo para análise da Gestão da Produção no ambiente intra e interorganizacional do Turismo. Revista Turismo \& Desenvolvimento, Portugal, v.1, n. 27-28, p.1563-1575. 2017.

PRAT, J.M.; CÀNOVES, G. Análisis de la Distribución Geográfica, a Nivel Comarcal, de los Alojamientos Turísticos del Pirineo Catalán Mediante la Aplicación de Algunos Índices de Concentración Geográfica. Revista de Análisis Turístico, v.1, n.17, 27-38, 2014.

SANTO, D.D. La Competitividad Turística en Espacios Interiores: una propuesta metodológica para la determinación de competidores potenciales. Cuadernos de Turismo, n. 30, p. 109-125, 2012.

SOTRATTI, M. A. O turismo como estratégia de desenvolvimento socioespacial: conexões e desconexões de áreas turistificadas com as dinâmicas socioespaciais das cidades. Caderno Virtual de Turismo. Edição especial: Hospitalidade e políticas públicas em turismo. Rio de Janeiro, v. 14, n.1, 39-51, 2014.

VON THÜNEN, J. H. The isolated state. Oxford: Pergamon Press, 1966.

WEBER, A. Theory of the location of industries. Chicago: Chicago University, 1969.

YIN, R. K. Case study research: design and methods. Beverly Hills: Sage, 2000 [1984].

Agradecimento: Pesquisa derivada de projeto aprovado e co-financiado pelo CNPQ (Chamada MCTIC/CNPq No 28/2018 - Edital Universal/Faixa A, processo no 438438/2018-3). 


\section{Thiago Duarte Pimentel}

Pós-Doutor em Sociologia (Teoria Social \& Realismo Crítico) pela Universidade Federal do Rio de Janeiro/UFRJ. Doutor em Ciências Sociais pela Universidade Federal de Juiz de Fora/UFJF. Mestre em Administração pela Universidade Federal de Minas Gerais/UFMG. Bacharel em Turismo pelo Instituto de Geociências da UFMG. Atualmente é professor associado na UFJF, onde também atua nos Programas de Pós-Graduação em Ciências Sociais (M/D) e em Administração Pública (Mestrado Profissional) e Privada (Mestrado Acadêmico).

Endereço institucional: Universidade Federal de Juiz de Fora. Instituto de Ciências Humanas, Sala: A-II-08. Rua José Lourenço Kelmer, São Pedro. CEP.:36036-330. Tel.: +55 (32) 984573093.

E-mail: thiago.pimentel@ich.ufjf.br

Recebido para publicação em agosto de 2020. Aprovado para publicação em junho de 2021. 